\title{
Accuracy and Cost Effectiveness of Manual and Automated Water-Level Monitoring Technology
}
M. D. Campbell
R. Schalla
D. R. Newcomer

March 1991

Prepared for the U.S. Department of Energy under Contract DE-AC06-76RLO 1830

Pacific Northwest Laboratory Operated for the U.S. Department of Energy by Battelle Memorial Institute 


\title{
DISCLAIMER
}

This report was prepared as an account of work sponsored by an agency of the United States Government. Neither the United States Government nor any agency thereof, nor Battelle Memorial Institute, nor any of their employees, makes any warranty, expressed or implied, or assumes any legal liability or responsibility for the accuracy, completeness, or usefulness of any information, apparatus, product, or process disciosed, or represents that its use would not infringe privately owned rights. Reference herein to any specific commercial product, process, or service by trade name, trademark, manufacturer, or otherwise does not necessarily constitute or imply its endorsement, recommendation, or favoring by the United States Government or any agency thereof, or Battelle Memorial Institute. The views and opinions of authors expressed herein do not necessarily state or reflect those of the United States Government or any agency thereof.

\author{
PACIFIC NORTHWEST LABORATORY \\ operated by \\ BATTELLE MEMORIAL INSTITUTE \\ for the \\ UNITED STATES DEPARTMENT OF ENERGY \\ under Contract DE.ACO6.76RLO 1830
}

Printed in the United States of America

Available to DOE and DOE contractors from the

Office of Scientific and Technical Information, P.O. Box 62, Oak Ridge, TN 37331; prices available from (615) 576-8401. FTS 626-8401.

Available to the public from the National Technical Information Service, U.S. Depariment of Commerce, 5285 Port Royal Rd, Springfieid, VA 22161. 
PNL-7566

UC -403

ACCURACY AND COST EFFECTIVENESS OF MANUAL AND AUTOMATED WATER-LEVEL

MONITORING TECHNOLOGY

M. D. Campbell

R. Schalla

D. R. Newcomer

March 1991

Prepared for

the U.S. Department of Energy under Contract DE-ACO6-76RLO 1830

Pacific Northwest Laboratory

Richland, Washington 99352 


\section{.}




\section{PREFACE}

This document was prepared as part of a composite report on site investigation technology applied to environmental restoration. However, because it applies to the wider spectrum of automated monitoring, it is presented alone. There is a brief assessment of several methods of measuring water level, followed by the results of tests made on commercially available dataloggers and transducers. 


\section{.}




\section{SUMMARY}

Relative water-surface elevations are used to characterize the unconfined aquifer beneath the Hanford Site. Because of the needed precision, most of these elevations were measured manually using steel tapes. The cost of these measurements alone average $\$ 9.00$ each. Simultaneous and frequent measurements in areas of rapid change have been avoided because of cost, even though both are important, and in some cases essential, for aquifer characterization.

The objective of this study was to evaluate, demonstrate, and report on the most cost-effective methods of obtaining water-level data for characterizing aquifers at hazardous waste sites. The goal was to reduce costs of characterizing and monitoring waste sites at the U.S. Department of Energy's Hanford Site.

Aquifer characterization is needed to define hydraulic flow gradients, which determine rate and direction of contaminant transport. Such characterization requires accurate measurements of groundwater elevation. An accuracy for water-level measurement within $\pm 0.01 \mathrm{ft}$ is recommended in the U.S. Environmental Protection Agency's Ground-Water Monitoring Technical Enforcement Guidance Document of the Resource Conservation and Recovery Act of 1976.

During fiscal year 1990, aquifer characterization was based on manua] measurements of groundwater levels in 810 wells at the Hanford Site, for a total of 5769 measurements. These measurements were made at various frequencies. Along the Columbia River or near the water disposal ponds and trenches at Hanford, where water levels fluctuate several feet each day, the highest frequency of measurement is needed. In certain cases, some researchers believe that hourly measurements are needed to characterize groundwater gradients. Automated datalogging equipment is essential for such locations and offers substantial benefits over manual measurements, including a lower cost per measurement.

An automated datalogging system consists of a transducer, a datalogger, a power supply, a radio transceiver, a data storage unit, and a computer. These components must be compatible with the wide range of measurement 
conditions existing at Hanford. Equipment should be durable, serviceable, versatile, and simple and have an overall resolution of $\pm 0.005 \mathrm{ft}$.

Staff at the Pacific Northwest Laboratory identified potentially suitable equipment and requested it from vendors for evaluation. Each piece of equipment was identified by a code letter to protect vendor identity. Instrument performance was compared with manufacturer's specifications and the above requirements. Precision, accuracy, hysteresis, and short-term drift were tested. Test results are summarized in this report.

Several suitable pieces of equipment were found. One of the 11 transducers tested had all the desired characteristics. Five of the nine dataloggers had adequate resolution, but only one qualified for all applications and transducers. An additional datalogger qualified for all applications using the 4- to 20-mA, current-1oop transducers. Other equipment lacked one or more essential features. Nearly all of the equipment tested performed according to manufacturer's specifications; but special needs, such as 4 -in. package diameter or vapor-tight seal, disqualified many of them. 


\section{ACKNOWLEDGMENTS}

We appreciate and acknowledge the assistance of many people in identifying current needs and in locating and evaluating suitable equipment. Vendors who provided equipment for this evaluation did so with the understanding that this activity was for equipment evaluation only. Nevertheless, they were very helpful in directing us to current or near-future products for consideration. Several current and former Pacific Northwest Laboratory (PNL) employees also provided assistance: $R$. W. Wallace helped identify and contact vendors and obtain literature; R. H. Severtsen and L. C. Harrison gave us 1 iterature, assessed needs, and gave us information on PNL's datalogger;

R. R. Kirkham reviewed the manuscript; E. A. Jacobson, J. F. McBride, and C. S. Cline also helped us. J. M. Gephart and others edited the manuscript. To a11, we express our thanks. 


\section{-}

,

,

' 


\section{CONTENTS}

PREFACE. .................... $i$ i $i$

SUMMARY. ...................

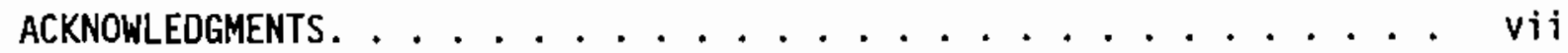

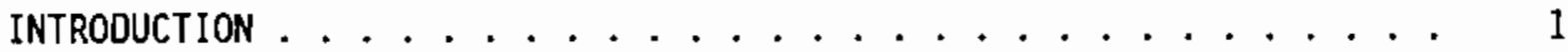

MEASUREMENT REQUIREMENTS ................. 5

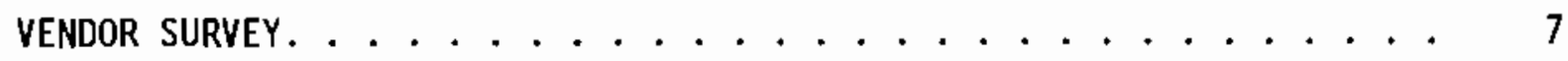

EQUIPMENT AND TESTING CONSIDERATIONS .............. 9

PERFORMANCE DEMONSTRATIONS ................. I3

SELECTION OF EQUIPMENT FOR DEMONSTRATION. . . . . . . . . 13

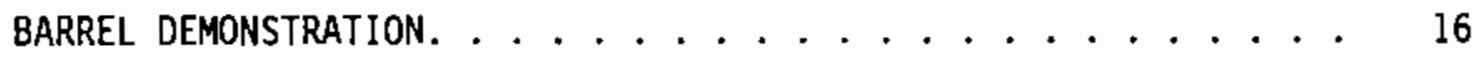

WATER COLUMN DEMONSTRATION. ......................... 18

OTHER DEMONSTRATIONS. . . . . . . . . . . . . . . 19

RESULTS AND DISCUSSION ...................... 21

CONCLUSIONS AND RECOMMENDATIONS. . . . . . . . . . . . . 37

REFERENCES ...................... 41 


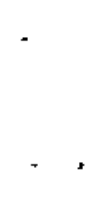




\section{FIGURES}

1 Millivolt Reference Cell Schematic............. 10

2 Current-to-Voltage Adapter Schematic ............ 11

3 Transducer Calibration Barrel and Water Column with Hook Gages and Fixtures .................... 16

4 Resolution of Datalogger 0 Output from 5-psi Transducer E. . . . 21

5 Resolution of Datalogger 0 Output from 10-psi Transducer D . . . 22

6 Resolution of Datalogger 0 Output from 15-psi Transducer C . . . 22

7 Deviations of Transducers $C$ and D from Known Reference Points. . 24

8 Deviations of Transducers $G$ and $E$ from Known Reference Points. . 25

9 Transducer A Sensitivity with Datalogger Q . . . . . . . 26

10 Transducer B Sensitivity with Datalogger T . . . . . . . . 27

Il Transducer H Sensitivity with Datalogger $0 \ldots 28$

12 Transducer F Sensitivity with Datalogger P . . . . . . . 28

13 Transducer F Drift and Hysteresis with Datalogger R. . . . . . 29

14 Transducer I Sensitivity Read on Vendor Frequency Meter. . . . . 30

15 Transducer J Sensitivity Read on Vendor Frequency Meter. . . . . . 30

I6 Transducer K Reading Barometric Pressure . . . . . . . . . . 31

17 Transducer K Measuring Water Evaporation from a 0.5-in.-Diameter Vertical Plastic Tube. ................. 31

18 Transducer K Measuring Single Water Droplet Additions to a 0.5-in.-Diameter Vertical Plastic Tube ......... 32

19 Resolution of Millivolt Signal Input to Datalogger S ..... 33

20 Datalogger U Resolution. . . . . . . . . . . . 35

21 Transducer Sensitivity Summary . . . . . . . . . . . 35

22 Datalogger Resolution Summary. . . . . . . . . . . 36 


\section{IABLE}

1 Water-Level Measuring Methods. . . . . . . . . . . . . 6 


\section{INTRODUCTION}

Measurement of water levels in aquifers is fundamental to groundwater investigations and is essential for hazardous waste site studies. When water levels are connected to a common survey datum, the water-level data can be converted to groundwater elevations. By knowing the groundwater elevations (or more accurately the hydraulic potentials resulting from them) at many points within the aquifer, flow direction can be determined. Flow direction, coupled with aquifer properties (i.e., transmissivity and effective porosity), allows accurate estimation of flow velocity. If flow velocity is known and the chemical behavior (e.g., biodegradation, adsorption) of contaminants are known, then their rate and direction of migration can be predicted. The ability to predict rate and extent of migration is essential for designing effective monitoring systems to detect and quantify the extent of contamination, and for designing remediation systems to decontaminate aquifers.

Water elevations in the unconfined aquifer beneath the Hanford Site must be measured accurately and frequently. Accuracy of $0.01 \mathrm{ft}$ was recommended by the U.S. Environmental Protection Agency as a standard (EPA 1986) and was adopted by administrators of the Resource Conservation and Recovery Act of 1976. A frequency of four times the natural fluctuation cycle appears to be about the minimum frequency from which extremes in elevation can be deduced. Historically, manual measurements provided the desired accuracy but not the required frequency. Conversely, automatic measurements provided the required frequency but not the desired accuracy. Consequently, manual measurements were used to obtain quality data, though few. In locations such as those near the river or near holding ponds, simultaneous measurements are needed to deduce flow direction. However, manual, simultaneous measurements are virtual Ty impossible. Also, the cost per data point from manual measurements has limited the quantity of data collected. More frequent, precise, and costeffective measurement methods are needed, particularly when measurement frequency exceeds one week.

Accuracy, frequency, and low cost of measurements are receiving emphasis in site characterization and remediation of the groundwater contamination 
problems at the Hanford Site and elsewhere. Perhaps it is this emphasis that has demonstrated the paucity of data on groundwater elevation more than any other. Whereas measurements taken once or twice a year have been common, there is now a need for much more frequent data.

The average cost of manual water-level measurement in a well at the Hanford Site is at least $\$ 9.00$ each, based on traveling $50 \mathrm{mi}$ and measuring 60 wells per workday. If a water level must be measured once each week or less frequently, manual measurements with a steel tape may be adequate and cost effective. However, automated data collection becomes cost effective when two or more measurements per week are required. For example, costs for hourly measurements are projected to be less than $\$ 0.20$ per data point. In addition, automated data collection could provide both more frequent and simultaneous readings. This may produce the synergistic effect of reducing the number of wells required to deduce flow without sacrificing essential information. This possibility needs further investigation through field demonstrations.

Staff at Pacific Northwest Laboratory (PNL) (a) followed five steps to define, locate, and evaluate automated equipment for measuring water levels. The evaluations were done in a laboratory where environmental conditions were only moderately variable. For example, temperatures varied about $2^{\circ} \mathrm{F}$ per day. Steps 1 through 4 pertain to equipment demonstrations reported here. Step 5 was performed subsequent to initial writing of this report and was followed by an extended field test (Campbell and Schalla 1990).

1. Outline measurements needed and instrument specifications.

2. Survey equipment vendors and request product literature.

3. Review product literature. Select at least two systems for demonstration, and test them as components and systems.

4. Analyze test results, and prepare a report showing system requirements and test results.

5. Identify qualified systems for field demonstration.

(a) Pacific Northwest Laboratory is operated for the U.S. Department of Energy by Battelle Memorial Institute. 
This report contains information about measurements, vendors, equipment, equipment tests, test results, and conclusions. A list is provided of measurements required and test characteristics of suitable measuring systems and components. The scheme we followed in locating vendors is reported, and a list of potential sources of equipment is included. Equipment demonstrations are outlined, followed by a discussion of results. Conclusions are drawn from the test data, and recommendations are made. 
- 


\section{MEASUREMENT REQUIREMENTS}

Initially, vendors were invited to demonstrate or submit for our test automatic water-level measuring equipment capable of long-term precision of $0.01 \mathrm{ft}$. Hanford Site needs were not specified until midway through the tests. Consequently, some equipment was tested that may be suitable for other sites but was found unsuitable for the Hanford Site.

The Hanford Site required automatic equipment suitable for the following: hydraulic gradients from 0.5 to about $45 \mathrm{ft} / \mathrm{mi}$, water-level change of $20 \mathrm{ft}$ in 3 months, temperatures from $-25^{\circ}$ to $+140^{\circ} \mathrm{F}$, with humidity ranging from dry to $100 \%$ and condensing. Monitoring sites are remote and without power or shelters.

Measurement systems must meet the following requirements:

- accuracy: $0.01 \mathrm{ft}$ of water elevation

- precision/resolution: $\pm 0.005 \mathrm{ft}$

- hysteresis/drift: $<0.005 \mathrm{ft}$

- range of water pressure to be measured: $\geq 20 \mathrm{ft}$

- size: transducer: $\leq 1$ in. outside diameter and $\leq 12$ in. long datalogger: capable of fitting inside a 4-in. pipe

- power supply or capacity: $\geq 3$ months of operation from a battery

- sample rate: $\leq 0.1 \mathrm{~s}$

- data storage: $\geq 8760$ data points with time and date

- durability: able to tolerate normal to rough handling during installation and servicing and to operate unattended for at least 3 months

- serviceability: capable of installation and routine field service by moderately trained technicians; capable of data retrieval and battery change without interrupting data collection; capable of transducer replacement without power interruption or el ement damage

- versatility: adaptable to battery, solar, or municipal power supplies; capable of current, voltage, frequency, and pulse measurements; capable of data storage and retrieval [including FM (frequency-modulated) radio telemetry]; tolerant of extreme 
environments with temperatures ranging from $-25^{\circ}$ to $+140^{\circ} \mathrm{F}$ and humidity ranging from dry to $100 \%$ and condensing

- simplicity: capable of use by technical personnel without special training or special precautions.

Trade magazines, professional journals, and commercial product catalogs were reviewed to develop a list of methods for measuring water levels. These methods are listed in Table 1.

\section{TABLE 1. Water-Level Measuring Methods}

Mechanical/electromechanical:

Invar steel tape: with chalk or electrodes

Steel cable: with markers, chalk, or electrodes

Stage recorder: with mechanical or electronic recording

Linear Variable Differential Transformer (LVDT) with float

Electrical resistance tape: with recorder

Pressure transducer:

Bubble gage: with Bourdon tube or electronic pressure transducer

Vibrating wire: piezoresistive; plucked, resonant

Bridge: voltage or with current transmitter

Quartz crystal: resonant

Variable capacitance

Force transducer:

Full bridge on beam: vibrating wire; plucked - buoyancy Optical:

Laser interferometer - reflective float

Helium-neon laser/mechanical scale and sensor

Fiber-optic reflective

Sonic:

Pressure wave/time lag

Acoustic holography: continuous, pulsed

Holographic interferometry 


\section{VENDOR SURVEY}

A list of vendors was developed using the Thomas Register and trade magazines. These vendors were contacted by telephone and queried about the suitability of their products for measuring water levels, particularly in wells. Product literature was requested from all vendors who could provide suitable products. That literature was reviewed, and a second list was prepared showing those vendors whose equipment met our specifications. These vendors were contacted by telephone and invited to provide their equipment for evaluation. Several vendors came to PNL and gave demonstrations; others sent their equipment or brought it and left it for evaluation. Each piece of equipment was identified by a code letter to protect vendor identity. Results are reported using the assigned code letter. 


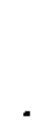

. 


\section{EQUIPMENT AND TESTING CONSIDERATIONS}

Vendors were invited to demonstrate, or submit for us to test, representative samples of their systems or components for measuring water levels automatically. No limitations were made regarding range. Sensitivity only was prescribed. Later, restrictions were applied to select equipment suitable for measuring water levels at the Hanford Site. Consequently, some equipment described here would qualify for monitoring wells elsewhere but would not qualify for monitoring Hanford wells.

Six vendors provided 11 transducers for demonstration. The 11 transducers were labeled for identification by the letters $A$ through $K$. The transducer ranges were from 0 to 1 to 0 to $50 \mathrm{psi}$ and included full-bridge voltage, current-1oop transmitter, and vibrating-wire pressure types. In addition, one vibrating-wire strain gage was used with a buoyant sinker. Transducer $K$ was not tested here, but three models of $i t$ were demonstrated for us at the factory.

The required operating range was unknown at the time vendors were invited to provide instruments to test. Consequently, some vendors sent their most sensitive transducers for evaluation, attempting to satisfy the stated resolution requirement of $0.01 \mathrm{ft}$. Later, one of the very sensitive transducers with a narrow range and relatively lower durability appeared less desirable than the more rugged ones capable of the full range of measurements. Nevertheless, all transducers submitted were tested.

The full-bridge voltage transducers received precisely regulated excitation voltage from the dataloggers used to read them. All transducers were monitored automatically on the most sensitive range suitable on the attached datalogger.

A millivolt reference was prepared using a D-size alkaline cell and three dropping resistors in series (shown in Figure 1). This millivolt reference was measured periodically using a digital multimeter with resolution to $\pm 1 \mu v$. During transducer tests, the millivolt reference was connected to the monitoring datalogger so it could be read as a reference voltage every time the transducers were read. Deviations in these readings 


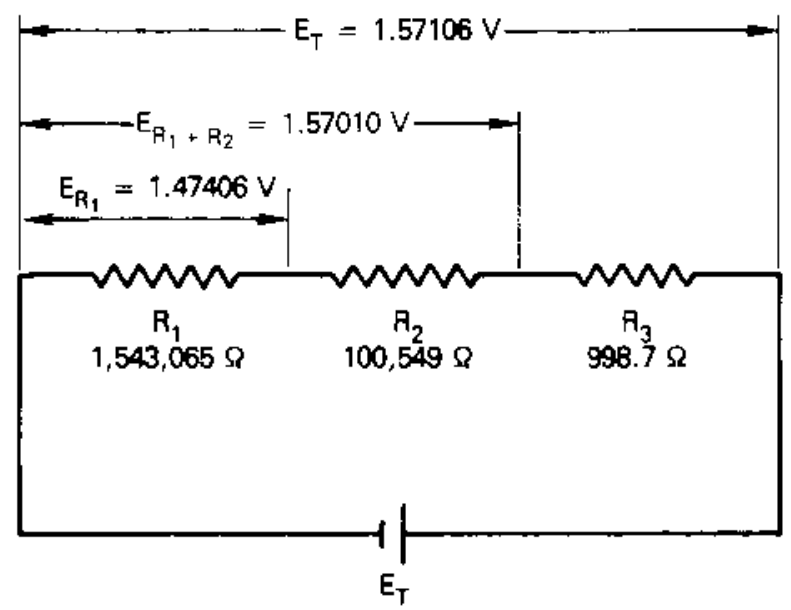

\section{FIGURE l. Millivolt Reference Cell Schematic}

were then reduced to equivalent transducer units and subtracted from the deviations of the transducer to remove datalogger influence from the test. The millivolt reference was again measured by the digital multimeter, which had calibration traceable to the National Bureau of Standards (NBS).

An adapter was made to convert current-loop transducer output to voltage. This was done by placing a 100-ohm dropping resistor in the negative leg of the circuit (shown in Figure 2) as directed by the manufacturer.

Parallel and serial outlets were provided for voltage and current measurements, respectively. During separate transducer testing, voltage drop across the resistor was input to a voltage datalogger, and an opposing voltage was applied to the dropping resistor. This permitted use of a lower range on the datalogger and resulted in higher resolution of the change in output signal from the transducer. With the higher resolution came a considerable increase in the signal to noise ratio. Consequently, signal averaging was used in some of the low-range datalogging.

In using the adapter, we were careful to avoid instrument interaction errors. The current meter had no observable influence on datalogger readings, but the digital voltmeter altered the datalogger readings slightly. Consequentiy, the datalogger and digital voltmeter were not connected to the adapter at the same time. 


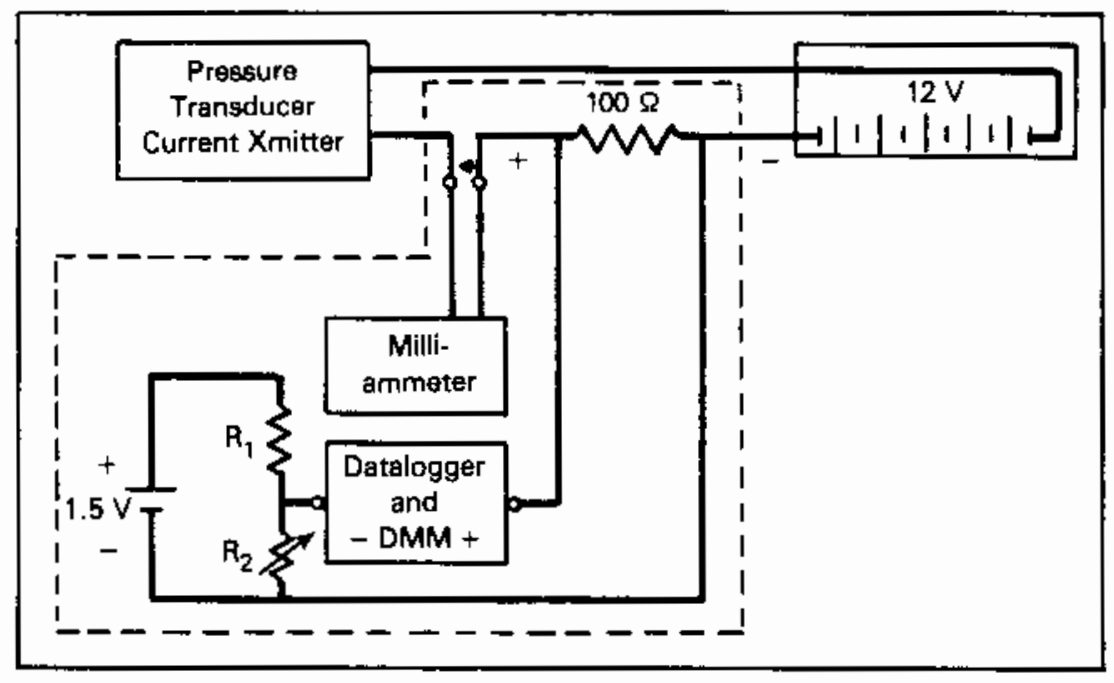

\section{FIGURE 2. Current-to-Voltage Adapter Schematic}

Nine dataloggers were demonstrated; six of these were tested here.

Dataloggers were identified by letters $N$ through $V$. Datalogger $N$ was not tested but was functionally demonstrated at PNL by the vendor. Although all dataloggers were to be tested in the same way, two of the dataloggers failed to function at PNL and were returned to the vendors. We invited the vendors to run the tests and send us the results for analysis. Data were plotted to show deviations of readings from input values.

System resolution was demonstrated by connecting each datalogger to a transducer. The transducer was displaced vertically by a hook-gage micrometer or by manualiy stepping along a fixed rod until the dataloggers changed readings several times. Where time permitted, water depth was measured and recorded during evaporation for several days. 
. 


\section{PERFORMANCE DEMONSTRATIONS}

Standard tests have been developed for various kinds of instruments used to measure water levels. These tests are used to certify the range and performance of equipment. For example, steel tapes are usually compared with a standard tape, and pressure transducers and load cells are commonly checked on a dead-weight tester. A dead-weight tester is a substitute device for delivering a standard pressure; it does not work for nonpressure instruments like buoyancy gages, however. We chose to use precise vertical displacement in water for our standard, and it worked well on all devices tested. However, in displaying the data graphically, it became apparent that we could not show the displacement steps because they were nonuniform, and there were too many to specify. If we displayed the steps themselves, then the deviations would not be visible and could not be shown. We therefore chose to indicate that there were steps, but we didn't specify their size or position. Our comments on the process follow.

\section{SELECTION OF EQUIPMENT FOR DEMONSTRATION}

Manually operated instruments (e.g., tape and cable instruments, with and without bell sounders) were not tested because they offer no improvement over steel tapes currently used to measure water levels. Simultaneous measurements are impossible, and day and night measurements are not feasible. Thus, we excluded manual instruments.

Stage recorders with counterweighted floats were disqualified because well size would not permit use of large enough floats to achieve required precision (Leupold and Stevens 1987). For example, a float system covering a 20- $\mathrm{ft}$ change in stage would need to be larger than 8 - $\mathrm{in}$. diameter to achieve a precision of $0.01 \mathrm{ft}$. Floats as small as $1.5 \mathrm{in}$. are available, but they have a float lag larger than $0.1 \mathrm{ft}$. Also, many wells at Hanford are not . vertical and straight enough to accept a float and cable without introducing friction from contact with the we11 casing, pump wires, or water pipe.

During these tests, we compared bubble gages with submersible pressure transducers. The five bubble gages were installed in parallel with five 
pressure transducers that were connected to a datalogger. The five bubble gages cost $\$ 3,130$ each, for a total of $\$ 15,650$. The five transducers cost $\$ 575$ each and the datalogger cost $\$ 1,250$, for a total of $\$ 4,125$, a factor greater than three times more expensive. In addition, the bubble gages required 5 to 10 times more maintenance than the pressure transducerdatalogger combination. Although the bubble gages we tested operated from battery power, their power consumption was relatively high, and they required frequent attention and adjustment to yield accurate data. Bubble gages may offer advantages when operating in dirty or corrosive liquids, but digital dataloggers would be required to replace the strip charts to make them competitive. Bubble gages were disqualified because of their high labor requirements.

The most commonly used resistance tapes were excluded because spacing of adjacent resistive loops was more than twice the $0.01-\mathrm{ft}$ tolerance limit. Also, the plastic jackets make the tapes very temperature sensitive by altering the closure pressure of the jacket and changing the zero point. Other negative factors were jacket deterioration and high replacement costs, about twice that of an equivalent submersible pressure transducer.

Bourdon-type gages were disqual ified because they demonstrated inherent drift and hysteresis; this restricts them to uses where measurements may vary up to $0.1 \mathrm{ft}$. However, they cost about half as much as a submersible pressure transducer, and they are available in either voltage or current-loop models.

Sonic transducers are capable of gathering precise data, and their working range can be adjusted if environmenta? temperature is suitably controlled. They are also available in systems capable of FM radio telemetry. Transducers with a wave guide were disqualified because they were too large for small wells, and those without a wave guide have poor resolution because of sound reflection interference. Transducers alone cost very little, but the collimator and other support equipment are expensive.

Linear Variable Differential Transformers (LVDTs) are capable of excellent precision with low drift, but most of them must remain above the water Tevel. They were excluded because of short range and the need to use some 
type of float with the limitations mentioned earlier. The LVDTs cost about the same as pressure or force transducers.

Capacitive transducers were excluded because of 1arge zero drift with temperature and unusual susceptibility to electrical noise, as from a pump. Compensation circuitry reduces these problems but not enough to meet Hanford needs. Cost was not considered.

Optical transducers are reported to be precise and stable, especially the helium-neon laser with split beam. The split-beam laser was not available for testing. It was disqualified because it was too bulky for small wells. The cost of an optical system was not determined.

Pressure transducers apparently have suitable characteristics. In fact, they bypass problems that would invalidate readings from other types of transducers, such as floating, dissolved, or suspended substances. Pressure transducers integrate all driving forces caused by pressure and density. Thus, oil floating a few feet thick on top of the water surface would still show the correct influence on the aquifer driving forces, even though the liquid surface level would not yield the correct information to one of the other transducers. A similar advantage is obtained from materials that alter liquid density but are miscible in water. Many of the pressure transducers range in diameter from 0.75 to $1.0 \mathrm{in}$. and from 4 to $12 \mathrm{in.}$ long. Although advertised for vertical axis use, they have an excellent record of performance in all positions. They can be placed in small or large wells and are available in voltage, current-loop, and vibrating-wire types that can be used in almost any electrical noise environment. Many of these transducers are temperature compensated with low drift. A few are specially adapted for submergence in polar, corrosive liquids. Several models are available with vents to the atmosphere during submergence in 1iquid. Costs range from about $\$ 10$ to $\$ 4300$; between $\$ 400$ and $\$ 900$ for models suitable for use at Hanford.

One type of pressure transducer deserves special comment. Quartz pressure transducers are advertised as being accurate, precise, stable, durable, serviceable, versatile, and simple. They are also the most expensive, with a unit price range from $\$ 2500$ to $\$ 4300$. Nevertheless, for long-term use where $0.005 \%$ of full-scale accuracy, precision, and drift are required over a wide 
temperature range with no maintenance, the quartz pressure transducer connected to a suitable datalogger offers a cost-effective measurement system. Its size disqualifies it for use in small wells, however, because it is larger than some floats.

After reviewing various types of water-level measuring devices and comparing their measurement principles and restrictions with the requirements previously stated, submersible pressure transducers with atmospheric vents were selected for demonstration. Ten transducers were demonstrated, including voltage, current-loop vibrating-wire, and load-cell models. A description of setups and demonstrations follows.

\section{BARREL DEMONSTRATION}

A 50-gal barrel cut in half (Figure 3 ) was placed on a bench in the laboratory. Two boards were placed across the middle to form a double bridge with about $2 \mathrm{in}$. of space in the middle for instruments. The half-barrel was filled with water to a depth of $1 \mathrm{ft}$.

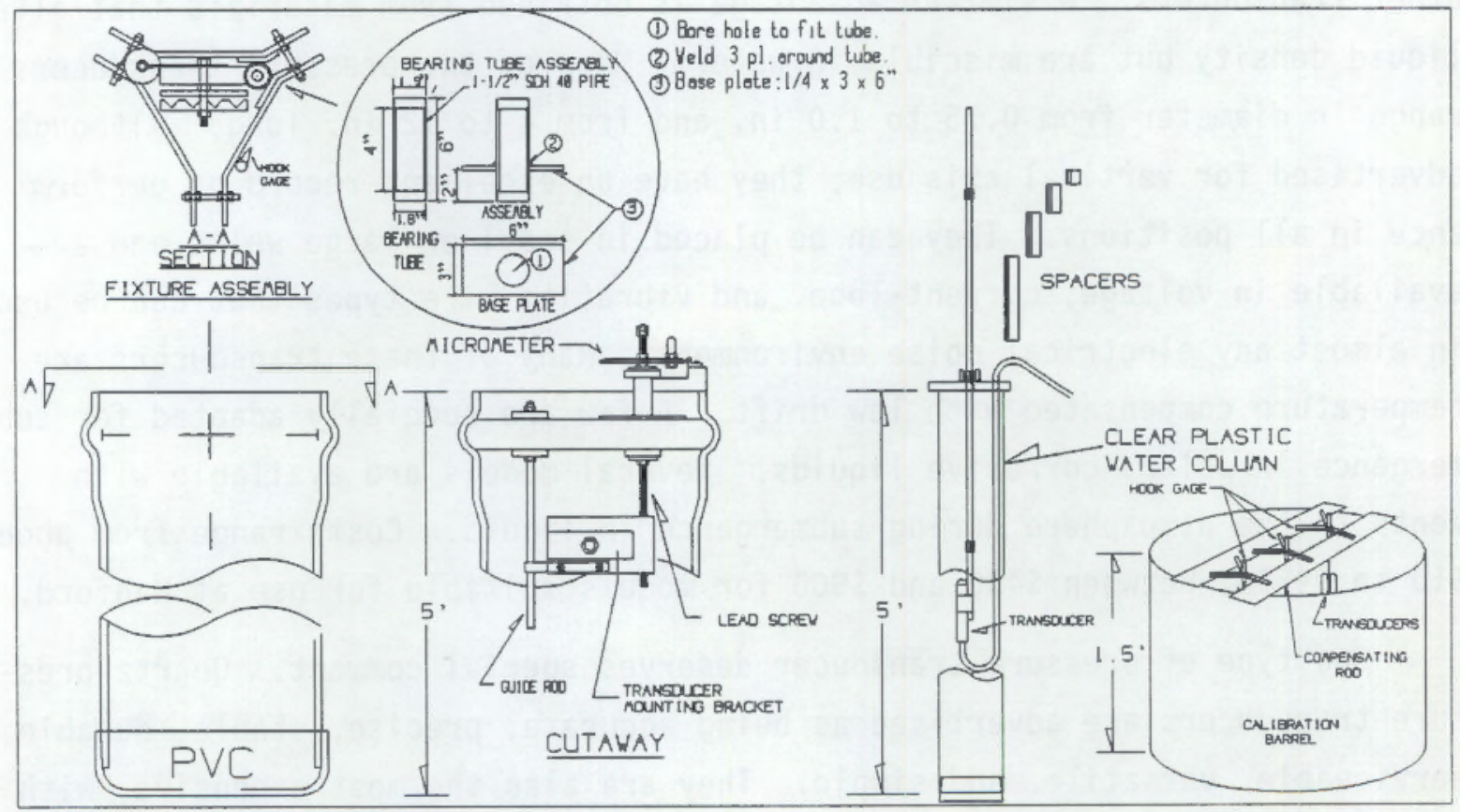

FIGURE 3. Transducer Calibration Barrel and Water Column with Hook Gages and Fixtures 
One hook gage was used to measure evaporation during the test of transducer $A$. For subsequent tests, three hook gages, like those used by the U.S. Weather Bureau for measuring class A pan evaporation, were fastened to the bridge with clamps: one hook gage was used for instrument displacement; the second hook gage was used to compensate for instrument displacement so the water level would remain constant (half-inch copper rods about $1 \mathrm{ft}$ long were fastened to these two hook gages by small hose clamps); and the third, unmodified hook gage was used to measure water levels.

A ring-stand clamp was used to fasten pressure transducers to the first copper rod so the transducers could be moved vertically by the hook gage. The second copper rod was moved in the opposite direction to compensate for water displacement.

Micrometers on the first two hook gages were set to initial positions and the readings were recorded. The water level in the half-barrel was measured using the third hook gage, and the value was recorded. The micrometers on the hook gages permitted displacements and direct readouts of water-level measurements to $0.00006 \mathrm{ft}$, with interpolation 20 times that precise. This setup was used primarily to test accuracy. Its secondary use was to test precision and hysteresis.

Transducers were connected to dataloggers that were programmed and placed in operation. A program was prepared for each test. For example, very high-resolution settings on the dataloggers made then so sensitive to electrical noise that it was necessary to time average the readings to get definitive measurements of transducer performance.

The following tasks were accomplished during the barrel demonstration:

- Transducers were tested for resolution, accuracy, hysteresis, and drift.

- Dataloggers were tested for resolution, accuracy, and drift.

- Data collected were adjusted using a reference voltage traceable to the NBS to separate performance of a datalogger from that of a transducer. 
- Measurements were processed to yield deviations (in feet) from known values and plotted to show performance of each component.

\section{WATER COLUMN DEMONSTRATION}

A 5-ft length of clear plastic pipe with a 4-in. outside diameter was plugged at the bottom with a rubber stopper and clamped to a laboratory bench. The plastic pipe was then filled nearly full of water. A steel strap $0.25 \times 3.0 \times 6.0$ in. was drilled and slotted in the middle and bolted to a short piece of 2 -in. angle iron to make a cover plate. This cover plate assembly was fastened to the top of the clear plastic pipe by a large hose clamp. A piece of wire, bent to form an S-shaped hook gage, was fastened under the large hose $\mathrm{clamp}$ and suspended in the water to provide a reference for the water level inside the tube. This water column was used primarily to test the pressure transducers for precision and hysteresis.

A 6-ft piece of 3/8-in. al1-thread rod was fitted with 5 pairs of nuts. These nuts were positioned at $1.000-\mathrm{ft}( \pm 0.0008-\mathrm{ft})$ intervals from one end of the rod and locked in place. Transducers were then fastened to the rod with tape. The rod was placed in the center slot of the cover plate assembly with the transducers suspended in the water.

The water level in the plastic pipe was adjusted to match the hook gage by using a plastic wash bottle to add water or a plastic siphon tube to remove it. Transducers were attached to dataloggers that were programmed and placed in operation.

A set of blocks was prepared to permit short-interval displacement of the transducers from their normal stop position on the double nuts. These blocks consisted of 3 blocks $0.3000 \mathrm{ft}$ long, 2 blocks $0.2000 \mathrm{ft}$ long, 2 blocks $0.1000 \mathrm{ft}$ long, and 4 blocks $0.0500 \mathrm{ft}$ long. Thus, each foot was divisible into 20 equal steps.

The length of the water column in the plastic pipe was sufficient to demonstrate full-scale operation of pressure transducers up to $2 \mathrm{psi}$. The other transducers could also be tested and their function certified over a larger range than that possible in the half-barrel. Use of the two setups permitted testing of transducers over precise displacement steps as small as 
$0.000003 \mathrm{ft}$ for accuracy and precision and over displacement steps as large as $3.5000 \mathrm{ft}$ for precision and hysteresis. Displacements were made small enough to test the resolution of the most sensitive dataloggers and the transducers. Transducer readings made in these setups were adjusted by subtracting the known displacement value and treating the remaining difference as a deviation from that step. Thus, most of the graphs display only the deviation from a step or a deviation from a step over time and do not show the step itself.

\section{OTHER DEMONSTRATIONS}

One transducer contained a vibrating wire that had to be "plucked" by electromagnetic induction. The transducer was connected to a buoyant sinker (a sealable tube with density adjustable to make it sink in water) that was suspended in water inside a steel pipe that was $10 \mathrm{ft}$ long and had a 4-in. inside diameter. Water displacements were read manually through a 3/4-in. inside diameter plastic tube fastened over a carpenter's steel tape. Resolution was uncertain, but was estimated to be $0.001 \mathrm{ft}$ or better by comparing readings with those from a machinist's scale.

Two other instruments demonstrated contained vibrating-wire transducers. One transducer had to remain stationary while the water pressure changed; this was done by using a glass funnel connected to the transducer input port by a piece of plastic tubing. The funnel was raised and lowered to preselected positions identified by hook gages that were fastened to a rigid frame and suspended over the vertical path of the funnel. The resolution of displacement was better than $0.0001 \mathrm{ft}$. The other vibrating-wire transducer was tested in the $5-\mathrm{ft}$ water column in the usual way, but was monitored by a frequency meter instead of a datalogger. 



\section{RESULTS AND DISCUSSION}

Eight of the nine dataloggers in this demonstration were digital and therefore discontinuous. Seven of the 11 transducers were analog and therefore continuous. A consequence of pairing discontinuous dataloggers with continuous transducers is that resulting transducer data are discontinuous. The separation between discontinuities is a measure of the resolution of the system. Because the dataloggers are the discontinuous element in the system, it is their resolution that was tested and displayed. Figures 4, 5, and 6 show the resolution of datalogger 0 connected to transducers $E, D$, and $C$. The up-sloping lines in Figures 4, 5, and 6 represent the change in water level with time resulting from evaporation; the water-level change was measured precisely by a hook gage. The horizontal lines represent readings recorded by the datalogger as evaporation occurred. Note that the horizontal lines are separated vertically by a fixed distance. Note also that the 5-, 10-, and 15-psi transducer readings are about $0.011,0.022$, and $0.033 \mathrm{ft}$

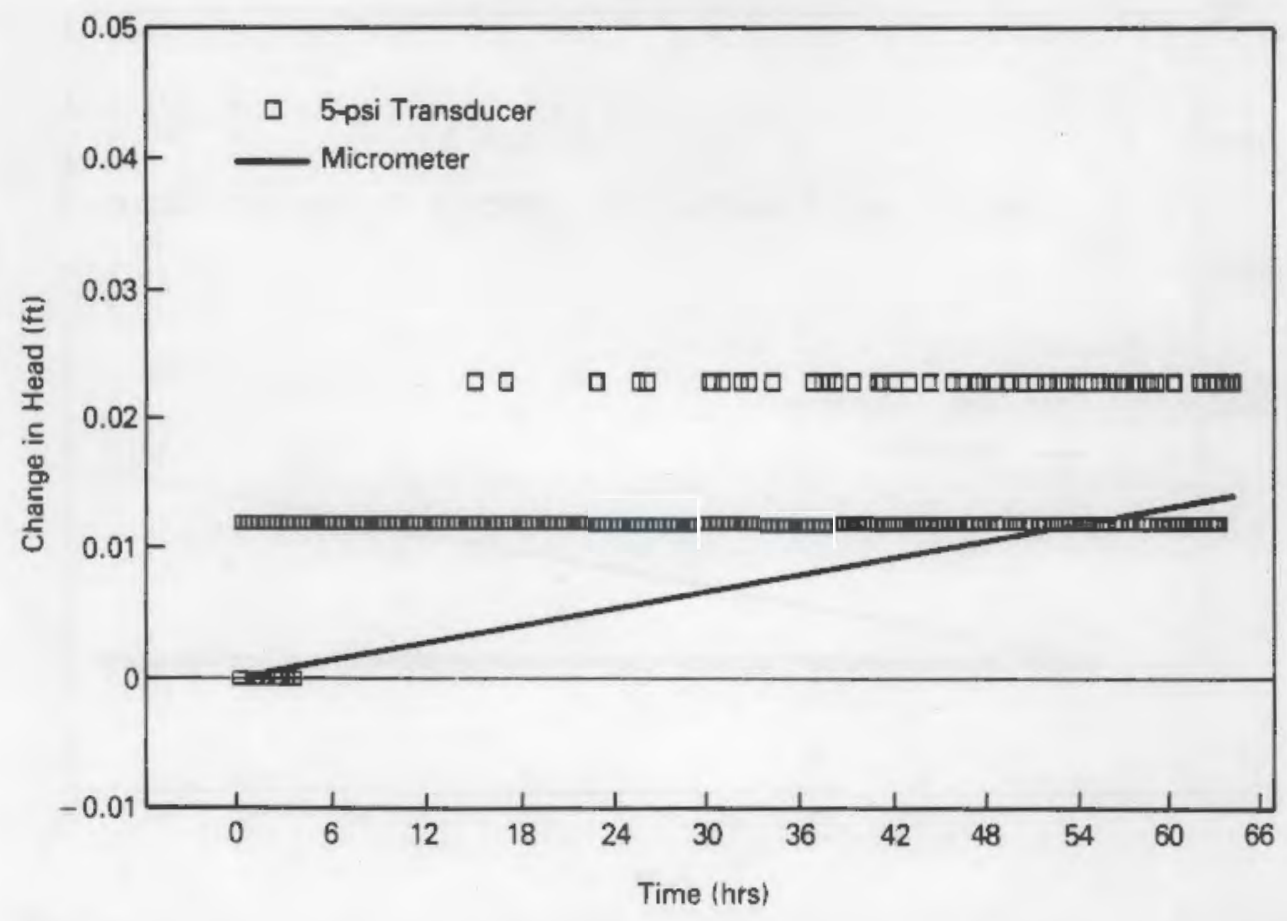

FIGURE 4. Resolution of Datalogger 0 Output from 5-psi Transducer E 


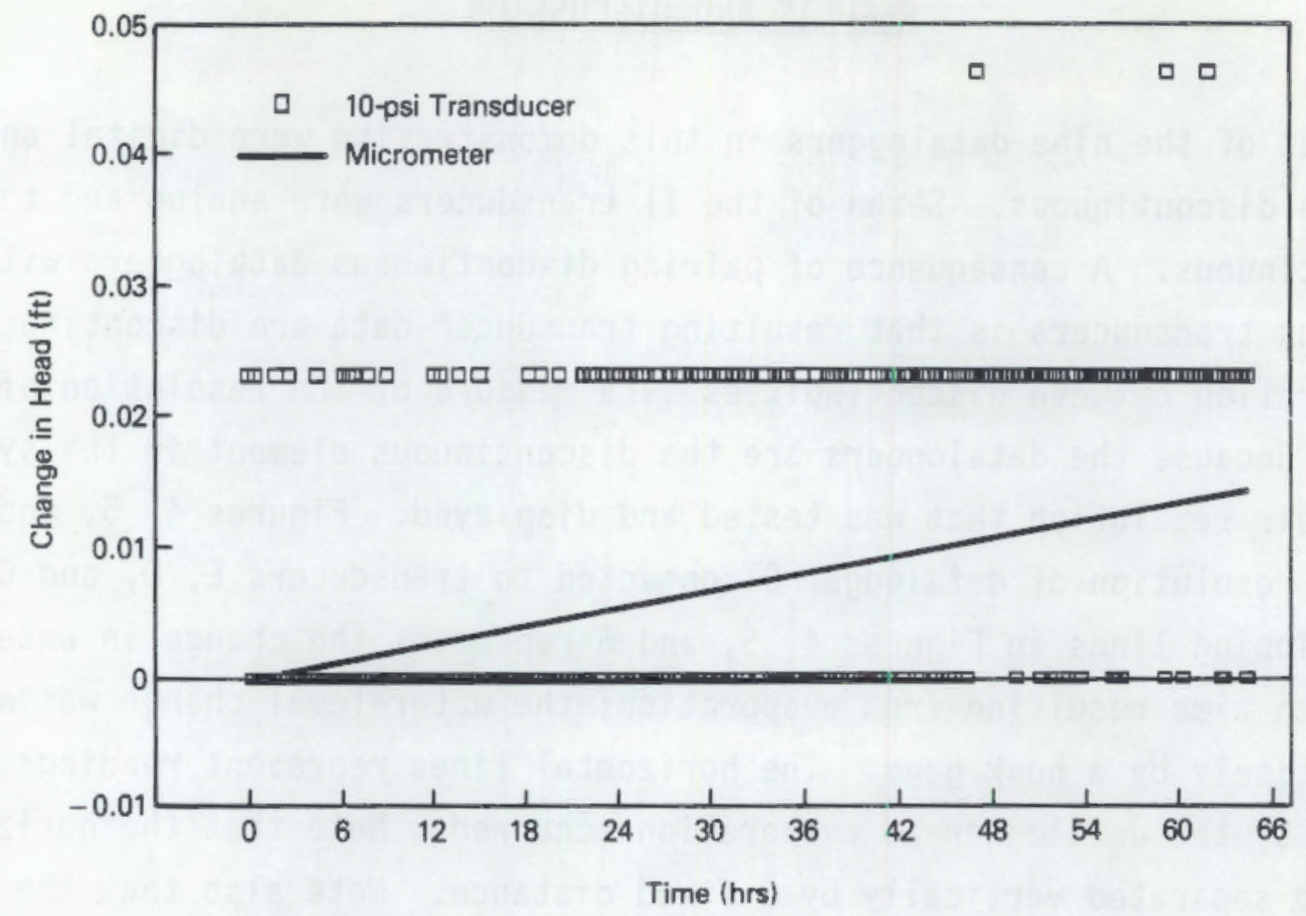

FIGURE 5. Resolution of Datalogger 0 Output from 10-psi Transducer D

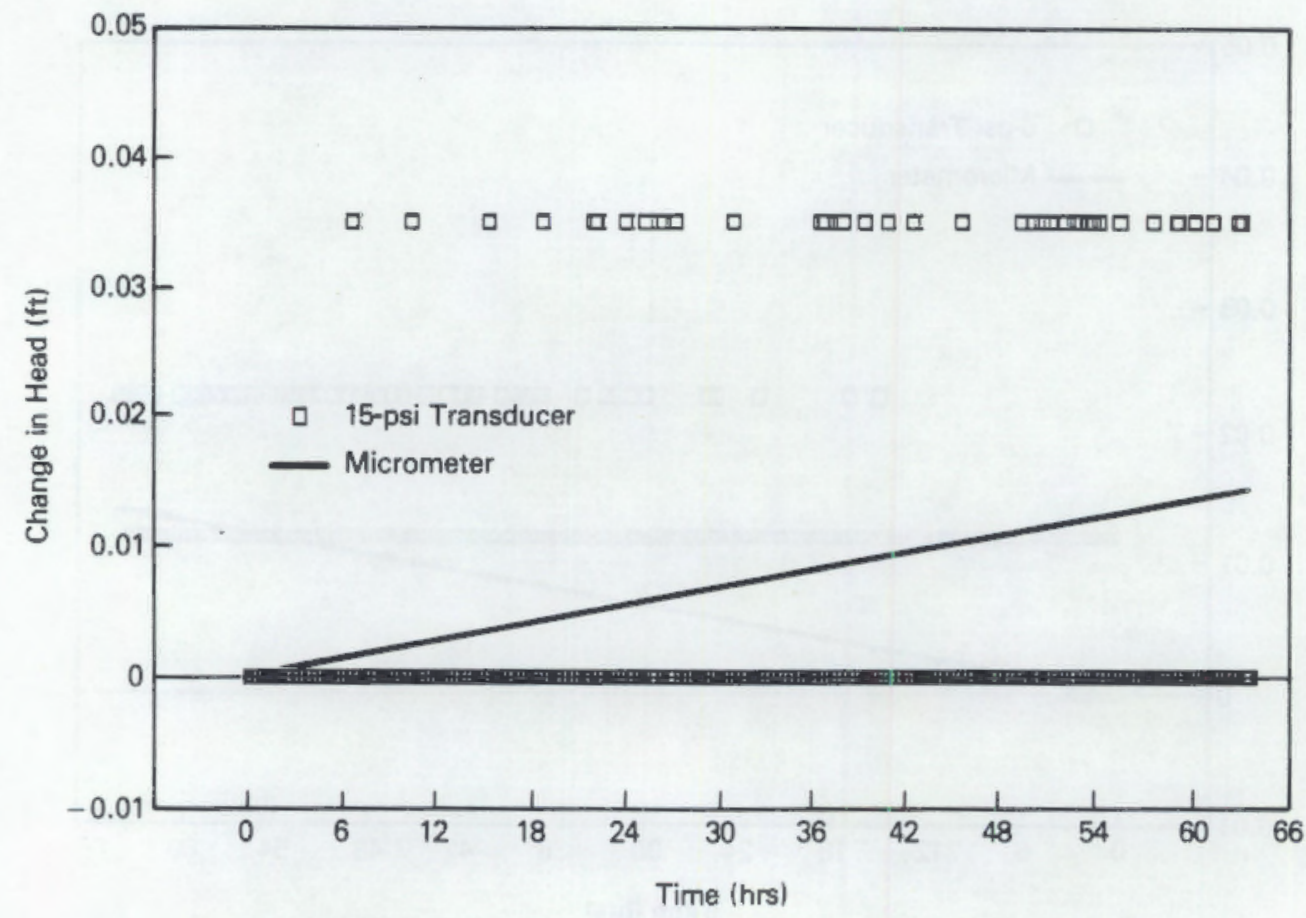

FIGURE 6. Resolution of Datalogger 0 Output from 15-psi Transducer C 
apart. A 10-psi transducer covers a range of $23.077 \mathrm{ft}$ of water depth. Thus, the resolution of the datalogger is about $23.077 / 0.023$ or about 1000 , based on visual inspection. The vendor confirmed that the datalogger was a 10-bit machine, which implies a resolution of 1 part in 1024 .

A datalogger resolving 1 part in 1024 will not meet the requirements set forth for Hanford groundwater measurements when used with any of these transducers because the resolution is too low. Also, the 5-psi transducer has insufficient range, unless $100 \%$ overranging is tolerable. These two conclusions taken together exclude such a datalogger from consideration, even though it performed according to vendor specifications. Thus, any datalogger that is 10 bit or lower is excluded, as is any transducer that reads less than 10 psi when fully overranging even if it is still in tolerance. Some transducers were demonstrated because of the possibility of using them in an overranging mode without loss of quality while preserving their inherently higher precision. For example, transducer $A$ has an overranging factor of 10; this range would be acceptable if it were otherwise acceptable.

Another factor is apparent in Figures 4, 5, and 6: the measurements recorded by the datalogger are not consistently along one line until a certain water-depth change forces them to the next line. Instead, they move alternately between two or three positions. This appears to be caused by digital rounding, electrical noise, displacement error, or nonlinearity (shown in Figure 7). Displacement was rechecked and found to be correct. Datalogger errors were separated from transducer errors by using the 16-bit datalogger $R$ and the reference voltage described earlier. The remaining error was in the transducers themselves. They did indeed fluctuate far enough to cause the original datalogger to shift randomly over the threereading range observed.(a)

(a) During review of graphic data, it is helpful to remember that transducers were moved in steps or water level was measured as water evaporated over time to change the readings. The readings were adjusted by subtracting the known displacement value and treating the remaining difference as a deviation. Thus, most of the figures display only the deviation from a step or a deviation from a water-level measurement over time. Steps are not shown in either case. Graphic results were autoscaled and are generally dissimilar until comparisons are displayed later in Figures 20 and 21. 


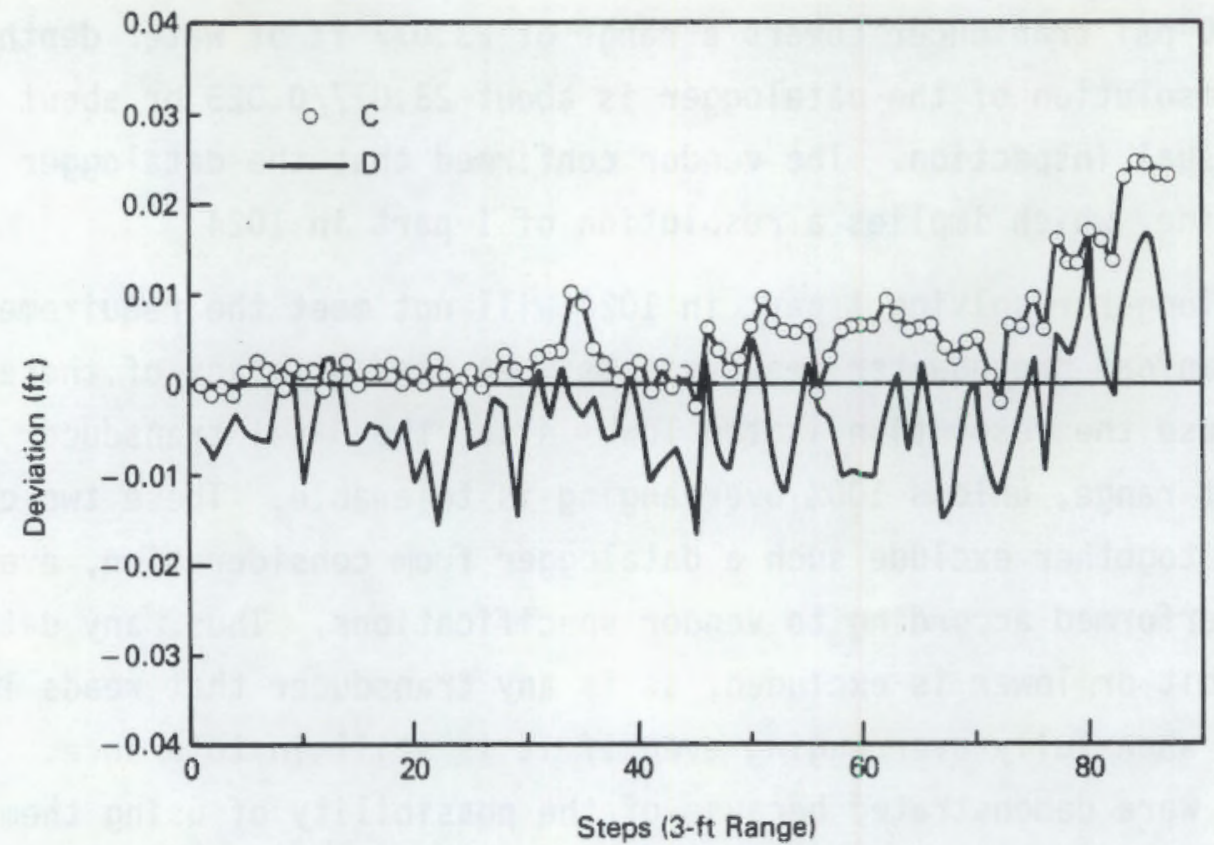

FIGURE 7. Deviations of Transducers C and D from Known Reference Points

Errors were observed from measurement systems in which transducer and datalogger were furnished by a single vendor, so the components were separated and tested to isolate the source of error. Transducers from one vendor were connected to a datalogger from another vendor. In addition, the voltage reference mentioned previously was input to the datalogger. The measurements taken are displayed as equivalent deviations in Figure 7. As described earlier, the voltage reference was measured by a calibrated digital multimeter and yielded a stable voltage to $\pm 1 \mu V$. The small reading errors from datalogger drift (though hardly distinguishable from zero on the graph) are shown in Figure 8 for reference, along with transducer performance. Note that reference voltage deviations were converted to specific transducer equivalent displacement values by dividing the transducer millivolt output per foot into the reference millivolt deviation. Transducer readings were corrected by removing datalogger error to show actual transducer performance, point by point. The inner lines in Figure 8 show deviations from known steps as the transducers were lowered into the water column. The outer lines 


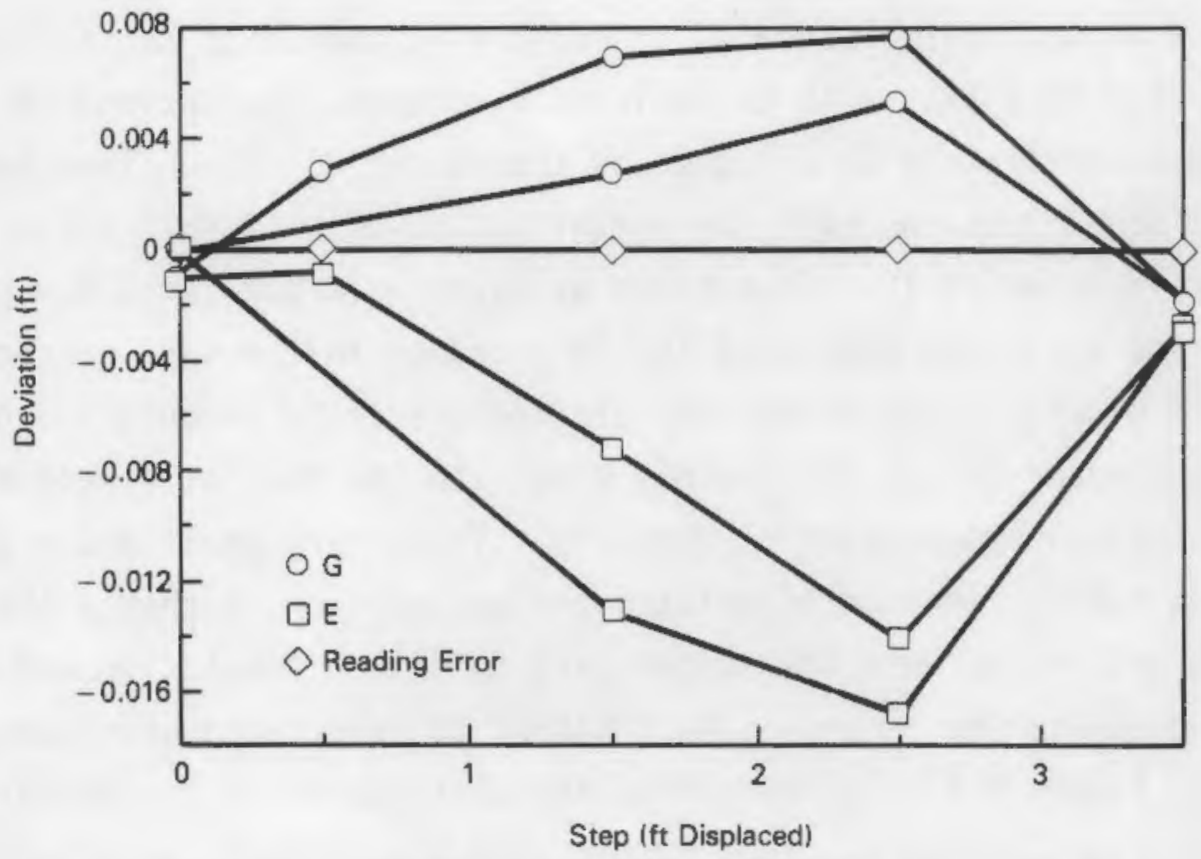

FIGURE 8. Deviations of Transducers $G$ and $E$ from Known Reference Points

represent deviations from the same steps during removal, thus displaying hysteresis. Reading deviations from the zero line are transducer inaccuracies.

Deviations of the datalogger measurements from the reference voltage are negl igible, even though they were taken on the highest range. However, the two transducers are outside the range of resolution needed, even though both are within advertised tolerance. The ranges of these two transducers are 0 to 1 and 0 to $5 \mathrm{psi}$; they are advertised as having infinite resolution, with precision of $1 \%$ and $0.25 \%$ of full scale, respectively. The problem with the transducers is a combination of nonlinearity and hysteresis over the $3.5-\mathrm{ft}$ range of the test. While the range of the test was outside that specified for transducer $G$, it is within the specified two times $(2 x)$ overrange limits. Return of the reading across the zero line confirms that mechanical distortion is negligible. If the similar hysteresis in the two transducers resulted from nonequilibration, then instrument response time is too long to meet the $\leq 0.1-\mathrm{s}$ response requirement by a factor greater than 300 . Finaliy, neither transducer has the needed range of $20 \mathrm{ft}$ with in tolerance. 
Figure 9 depicts performance of transducer $A$, the first one tested. It had a range of 0 to 1 psi, with unspecified overrange. Deviations of transducer A were approximately $1 \%$ as large as transducer G, though they had the same range. Specifications call for deviations of $0.1 \%$ of full scale. Overranging specification is $10 \mathrm{x}$, five times as large as $G$ and large enough to replace $E$. The variation displayed led to a change in the test procedure so that we could displace transducers rapidly and precisely in both the halfbarrel and the water column and thereby eliminate the possibility of errors caused by shifts in temperature or humidity. Thus, very small depth changes could be made rapidly instead of waiting for evaporation to change the water level. Both procedures were thereafter used to detect resolution and drift. In general, displacement sequences were varied to detect and eliminate error; nevertheless, Figure 9 fairly represents the performance of transducer $A$.

The other transducers that were demonstrated had adequate range and unexpected precision and stability. Transducer $B$, for example, had a range of $15 \mathrm{psi}$ and demonstrated acceptable precision when used with datalogger $T$ (Figure 10). The transducer range of $34.60 \mathrm{ft}$ required resolution of 1 part

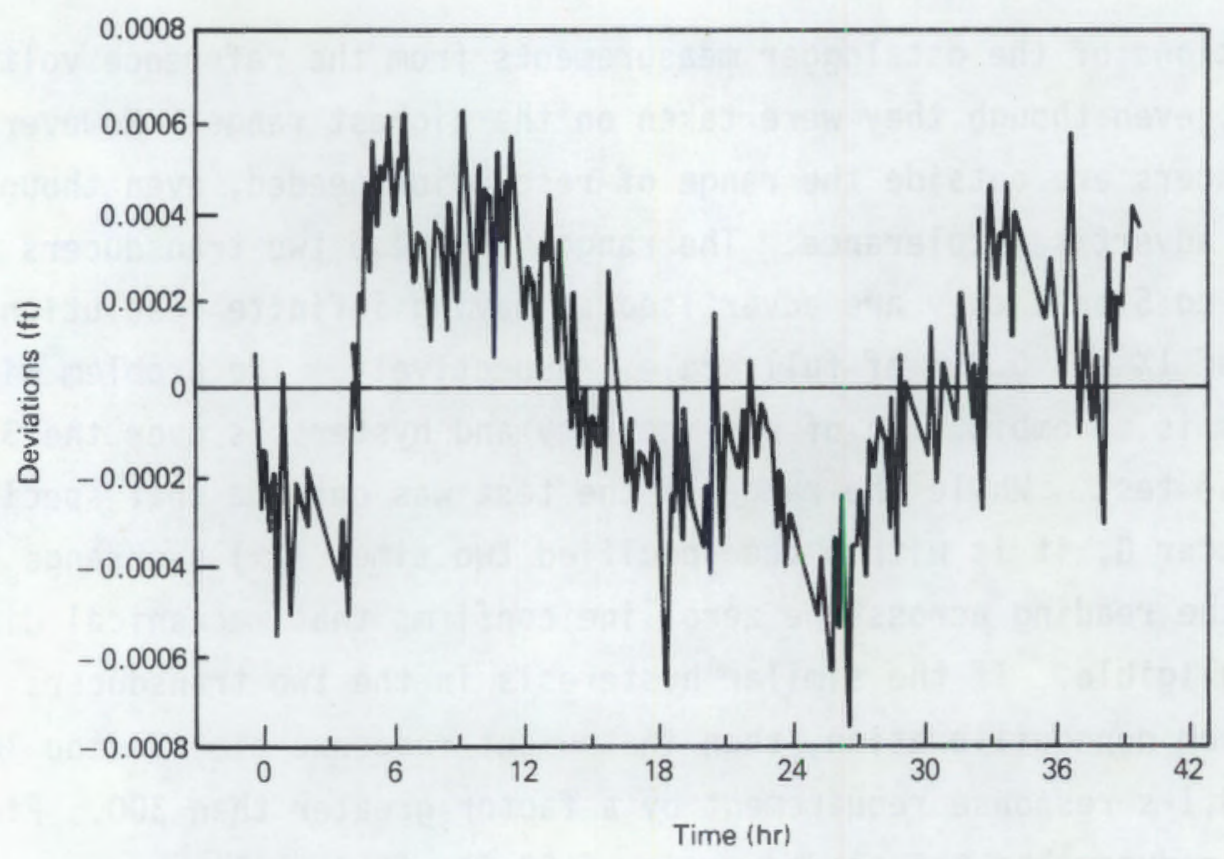

FIGURE 9. Transducer A Sensitivity with Datalogger Q 


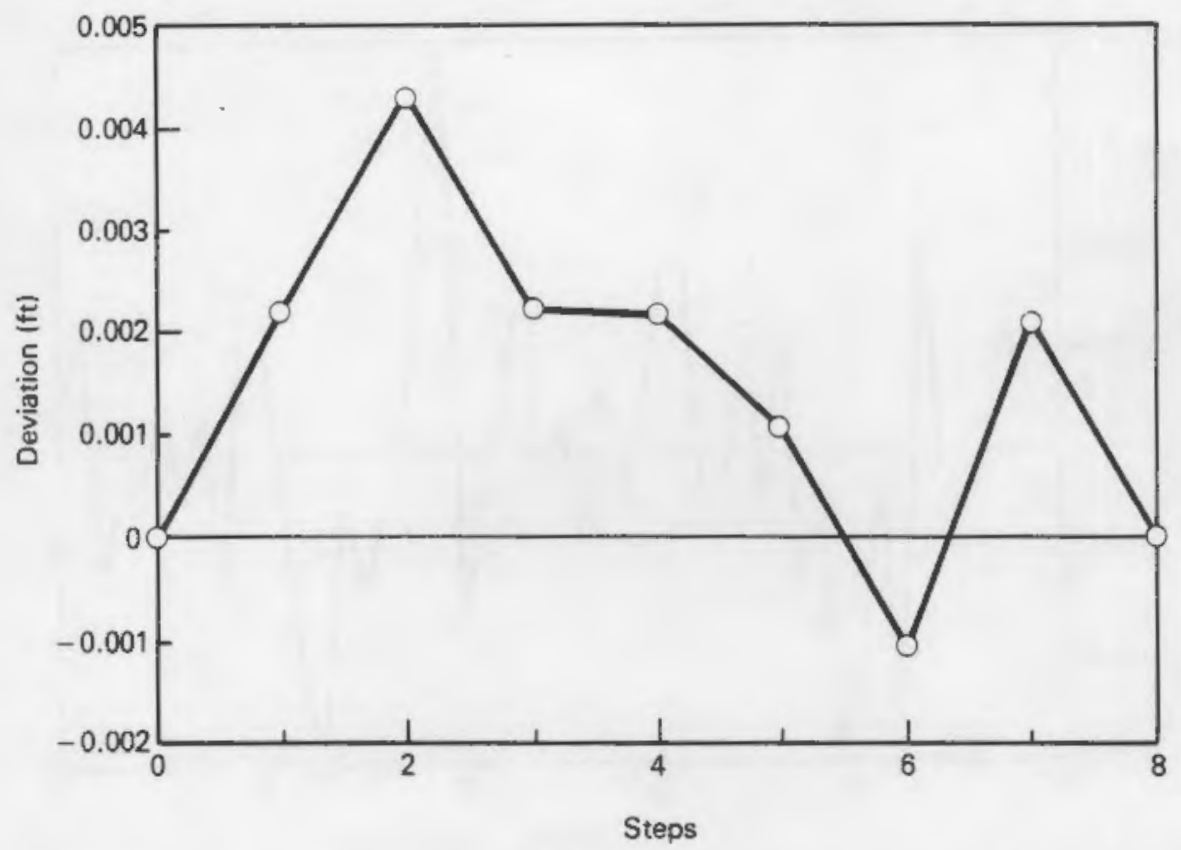

FIGURE 10. Transducer B Sensitivity with Datalogger T

in 6920. Therefore, datalogger $T$ was also acceptable, and it performed better than its specified 12-bit resolution.

Transducer $\mathrm{H}$ demonstrated acceptable performance when used with datalogger Q (Figure 11). This transducer, while not a submersible model, is available in a submersible model and would work well with a bubble gage. It was tested using a funnel attached to the transducer by a plastic tube. Results shown in Figure 11 represent precision and hysteresis only. The datalogger was a 12-bit machine, which met the requirements previously specified.

Transducer $F$ performed questionably (Figure 12) when connected to datalogger $P$, which is a 12-bit machine. Drift is evident in Figure 12, but a11 readings appear to be in tolerance. Because of the amount of drift over the short-range displacement made during this test, an additional test was run, using a different datalogger and the millivolt reference over a 3-ft range. Results are shown in Figure 13. Even though this performance is not good enough to meet the \pm 0.005 - $\mathrm{ft}$ application requirement, it is within $0.05 \%$ of full scale, which is well within vendor specifications. Hysteresis 


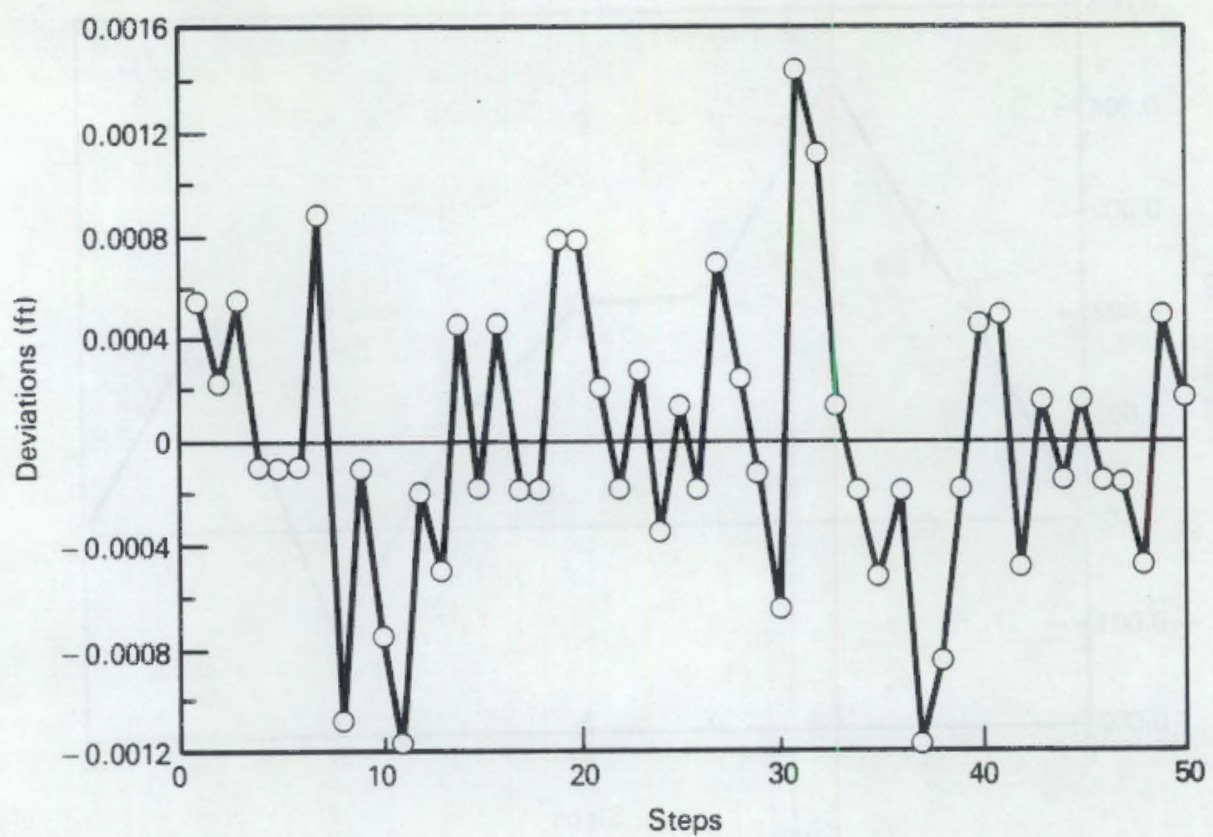

FIGURE 11. Transducer H Sensitivity with Datalogger Q

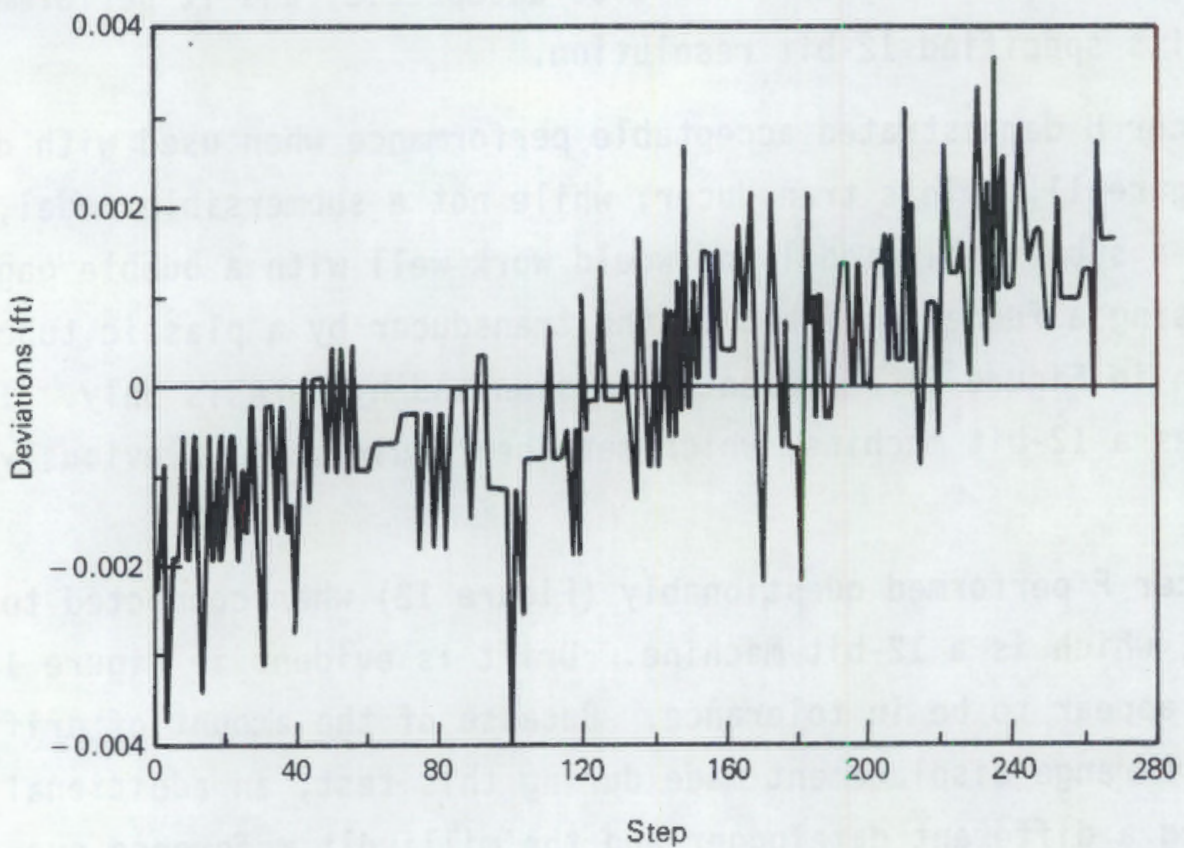

FIGURE 12. Transducer $F$ Sensitivity with Datalogger $P$ 


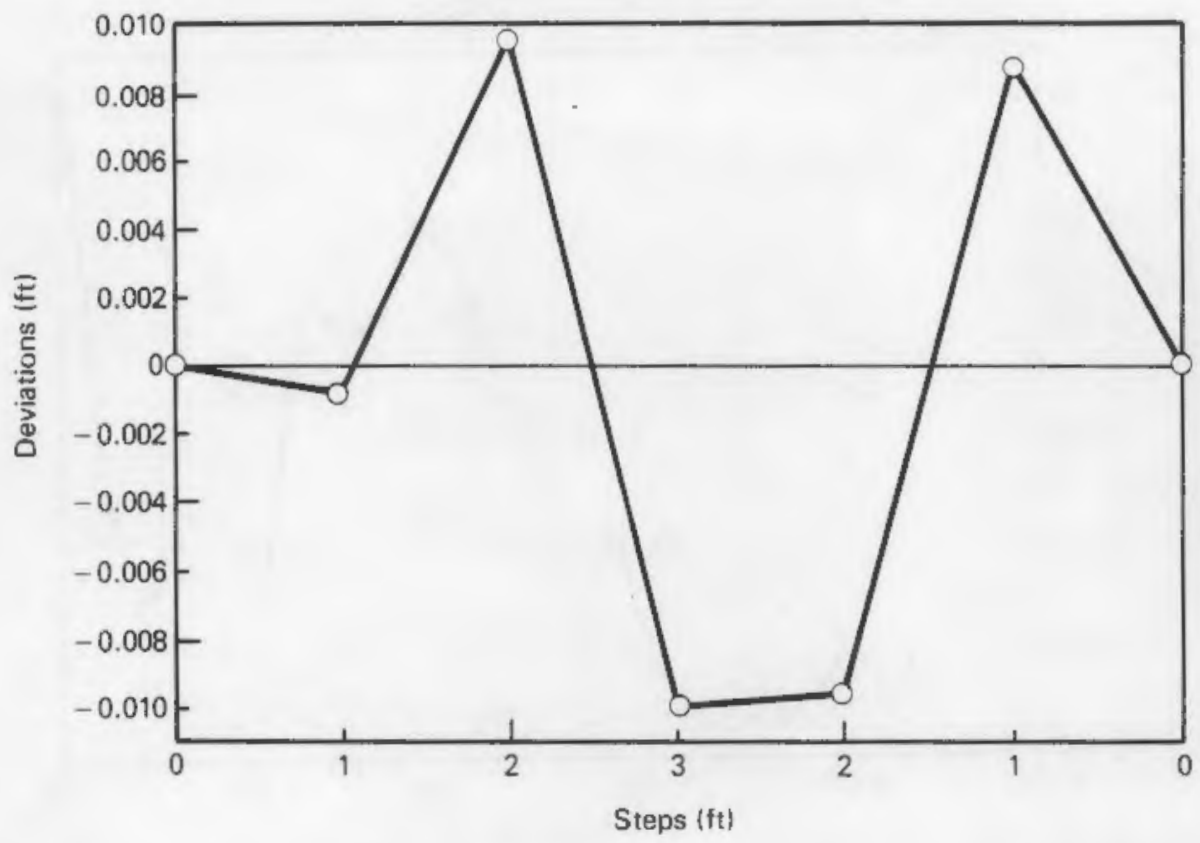

FIGURE 13. Transducer F Drift and Hysteresis with Datalogger R

in transducer $F$ is apparent, but we could not absolutely exclude all datalogger influence beyond the fourth reading. Consequently, we did not show the error as transducer hysteresis as we did in Figure 8.

Transducers $I$ and $\mathrm{J}$ were tested with a manually read frequency meter, provided by the vendor for the demonstration (shown in Figures 14 and 15, respectively). No other cross checking was attempted. Both transducers are within vendor specifications; however, the buoyancy transducer has too short a range and too large a diameter to meet the stated needs. The other unit has five times the needed range and approximately half the required precision. Transducer I had a range of about $7 \mathrm{ft}$, while $\mathrm{J}$ had a range of $115 \mathrm{ft}$.

Transducer $K$ demonstrated excellent characteristics. However, results appear different from others displayed here because the demonstrations were done at the factory rather than on our test equipment. Nevertheless, resolution, precision, and hysteresis appeared to be acceptable for our application and substantially better than any other transducer tested. Figure 16 shows barometric pressure on August 6,1988 , to demonstrate sensitivity. Figure 17 shows water pressure loss resulting from evaporation from a 0.5 -in.-diameter plastic tube; this figure also displays instrument sensitivity. Figure 18 


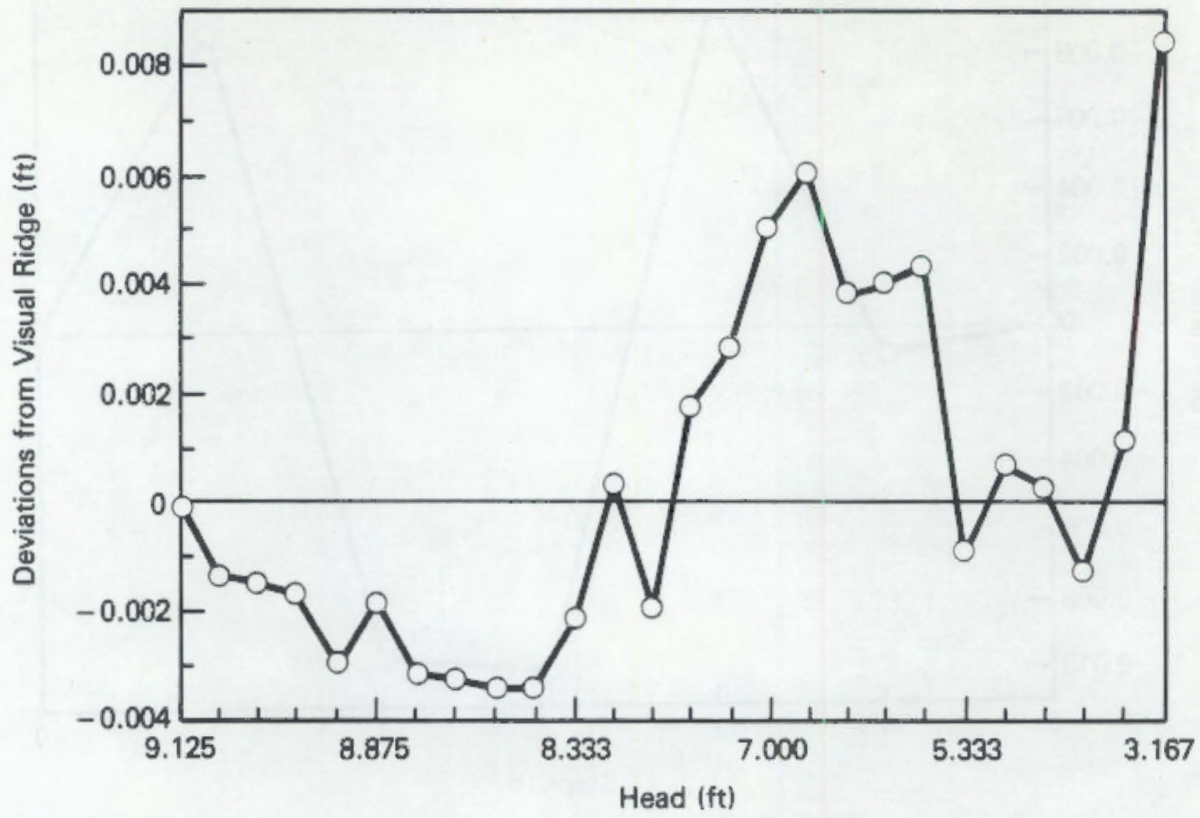

FIGURE 14. Transducer I Sensitivity Read on Vendor Frequency Meter

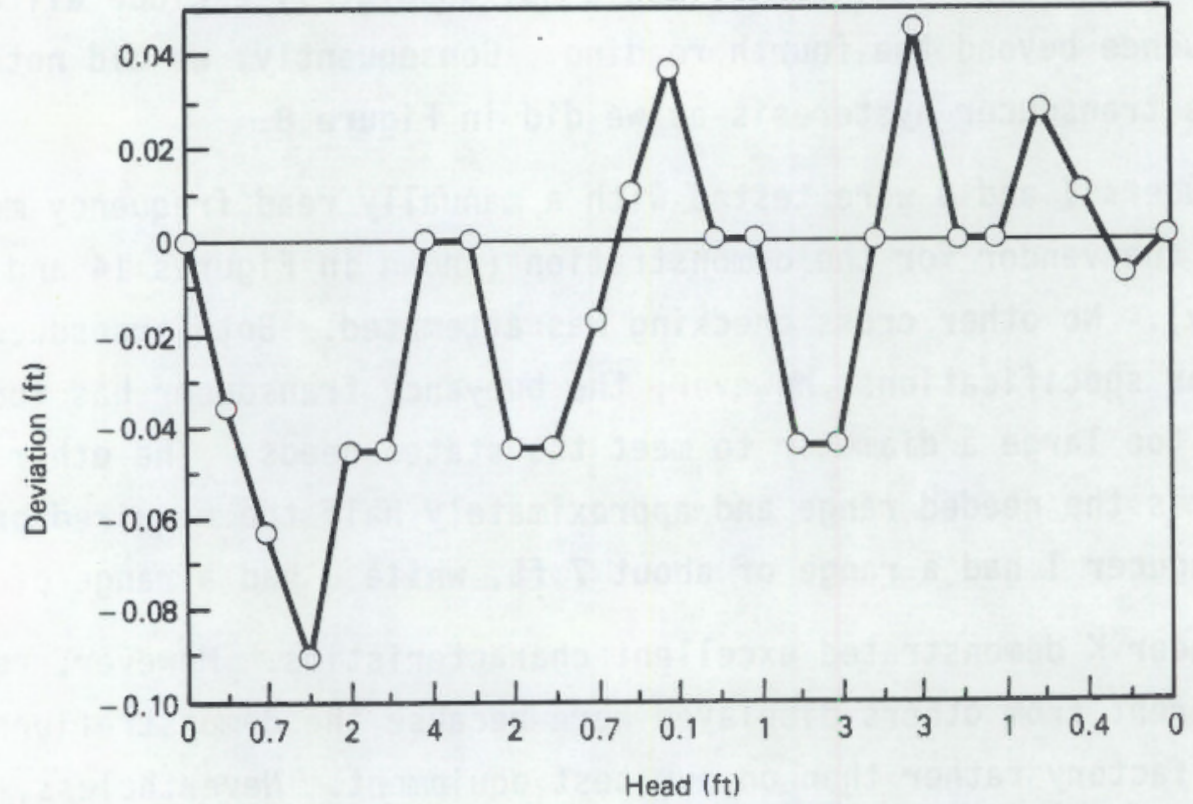

FIGURE 15. Transducer J Sensitivity Read on Vendor Frequency Meter 


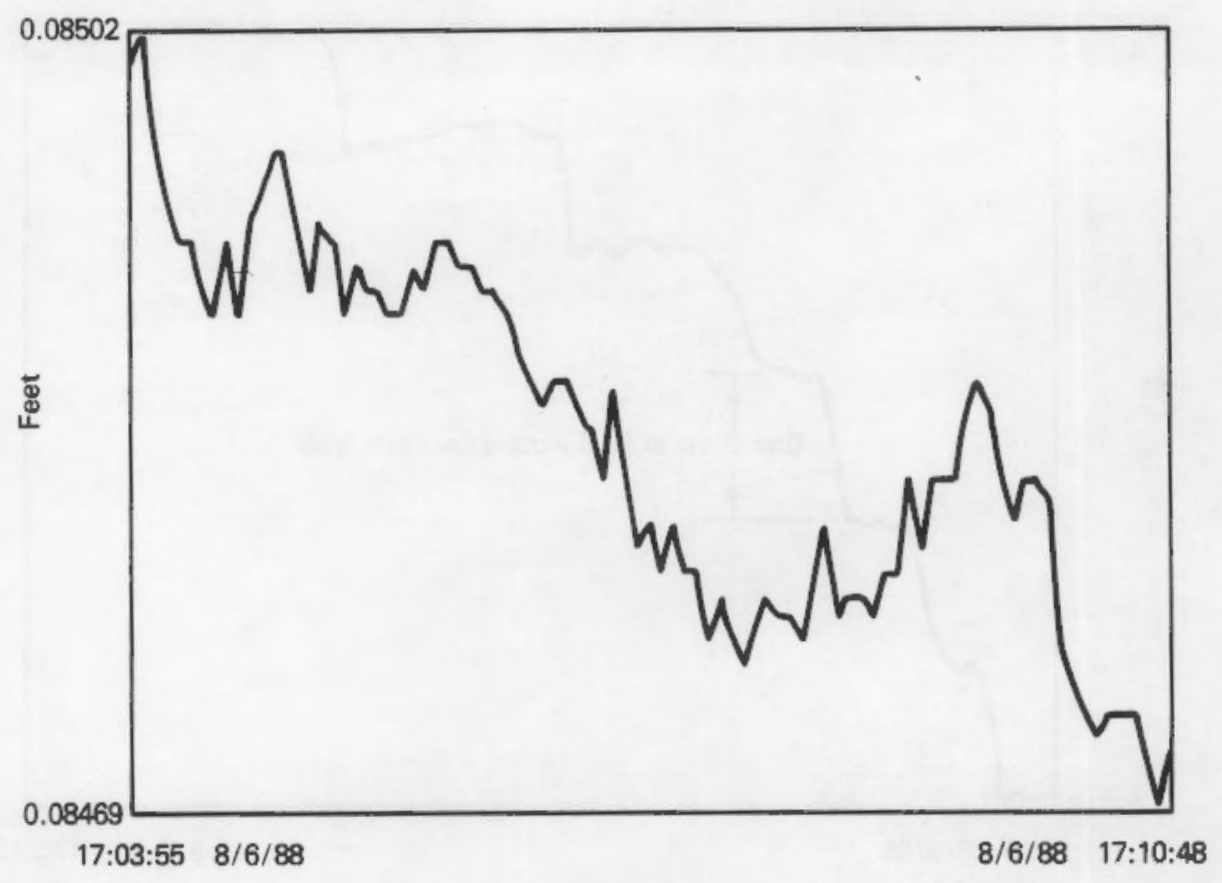

FIGURE 16. Transducer K Reading Barometric Pressure

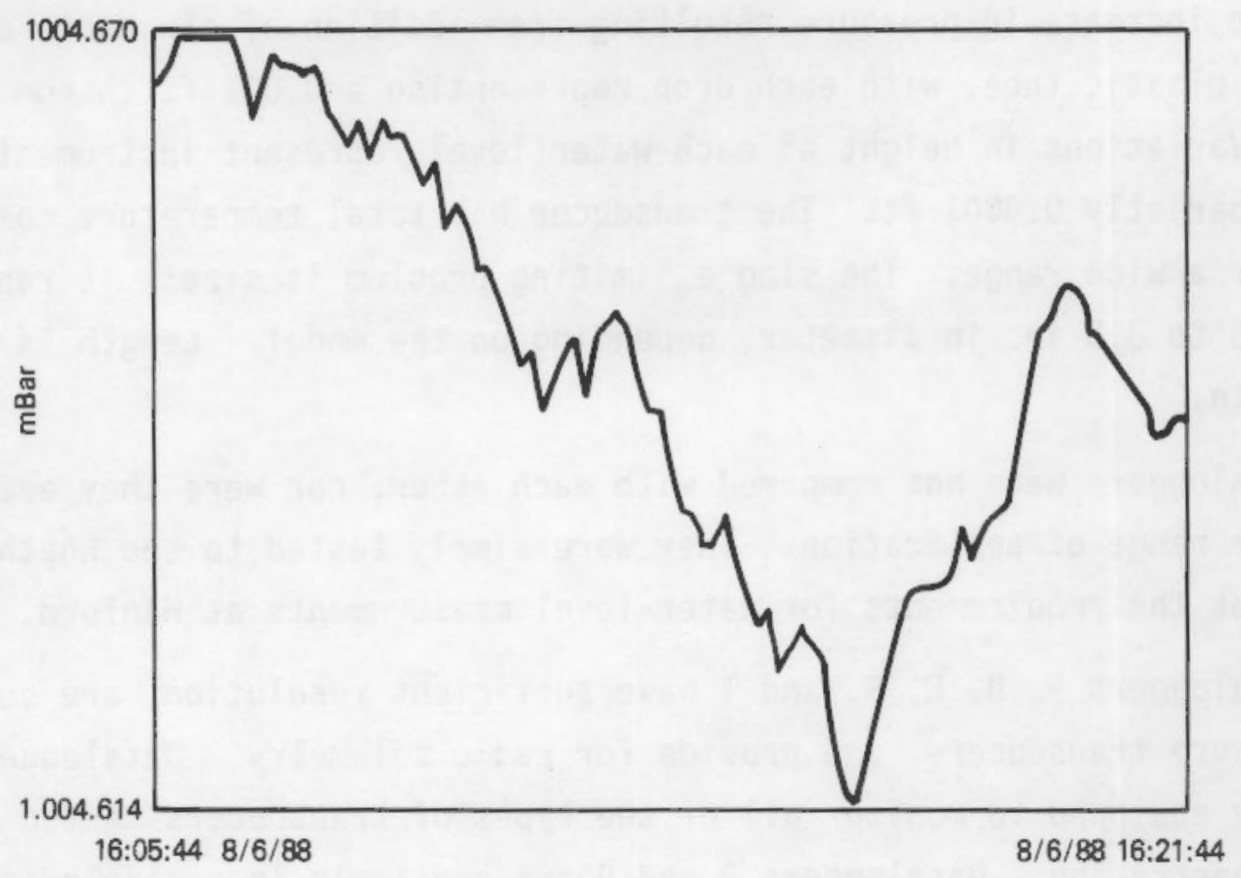

FIGURE 17. Transducer $K$ Measuring Water Evaporation from a 0.5-in.-Diameter Vertical Plastic Tube 


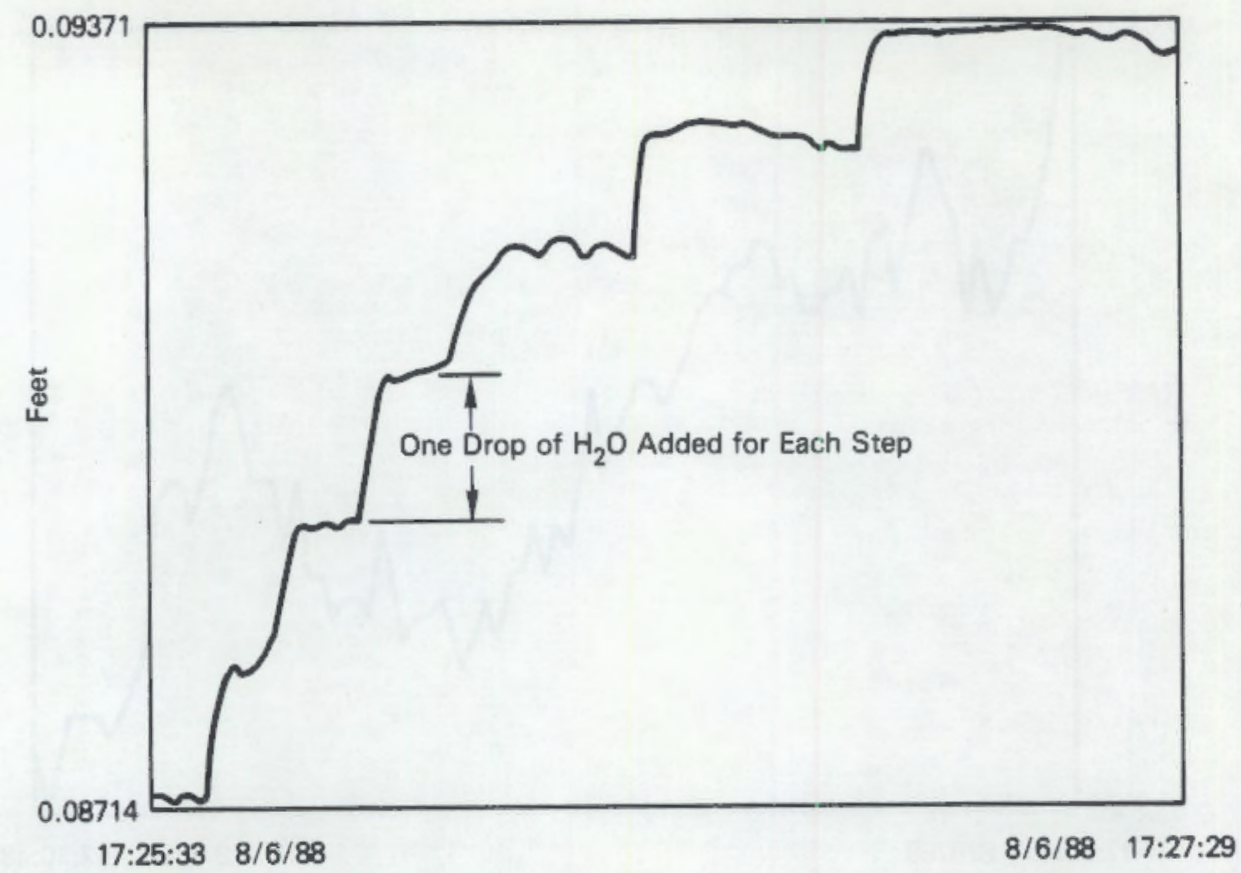

FIGURE 18. Transducer K Measuring Single Water Droplet Additions to a 0.5 -in.-Diameter Vertical P1astic Tube

shows the increase in pressure resulting from addition of six drops of water into the plastic tube, with each drop representing a $0.001-\mathrm{ft}$ change in water depth. Variations in height at each water level represent instrument resolution, apparently $0.0001 \mathrm{ft}$. The transducer has total temperature compensation over a wide range. The single limiting problem is size: it ranges from about 1.5 to $3.5 \mathrm{in}$. in diameter, depending on the model. Length is acceptable.

Dataloggers were not compared with each other, nor were they evaluated for their range of application. They were simply tested to see whether they could meet the requirements for water-level measurements at Hanford.

Dataloggers P, Q, R, S, and T have sufficient resolution, are suitable for pressure transducers, and provide for radio telemetry. Datalogger $Q$ is currently equipped to monitor all of the types of transducers tested during this demonstration. Dataloggers $P$ and $Q$ are available in sealable, cylindrical enclosures that fit inside a 4-in. well casing. While others had weather enclosures, they were too large for the well casing. 
Dataloggers $\mathrm{N}, \mathrm{S}, \mathrm{U}$, and $\mathrm{V}$ require further comments. Although datalogger $\mathrm{N}$ was demonstrated here by the vendor, it was not functionally tested for resolution. However, it had a weather tight, steel enclosure and is available in models with 12-bit and higher resolution. It also has FM radio telemetry capability available.

Datalogger $S$ failed as it was being programmed and was returned to the factory for repair. The vendor was unable to find anything wrong. Data were taken at our request and sent to us for analysis; results are shown in Figure 19. Evidently the datalogger is capable of resolving more than 1 part in 4000 . It has a weathertight, shock-resistant plastic enclosure and an easily replaceable data module and battery pack that can be replaced without interruption. It also has a menu-driven programming process that is simple to use. This datalogger is small, rugged, and suitable for use with radio telemetry equipment. However, its scan interval is too long.

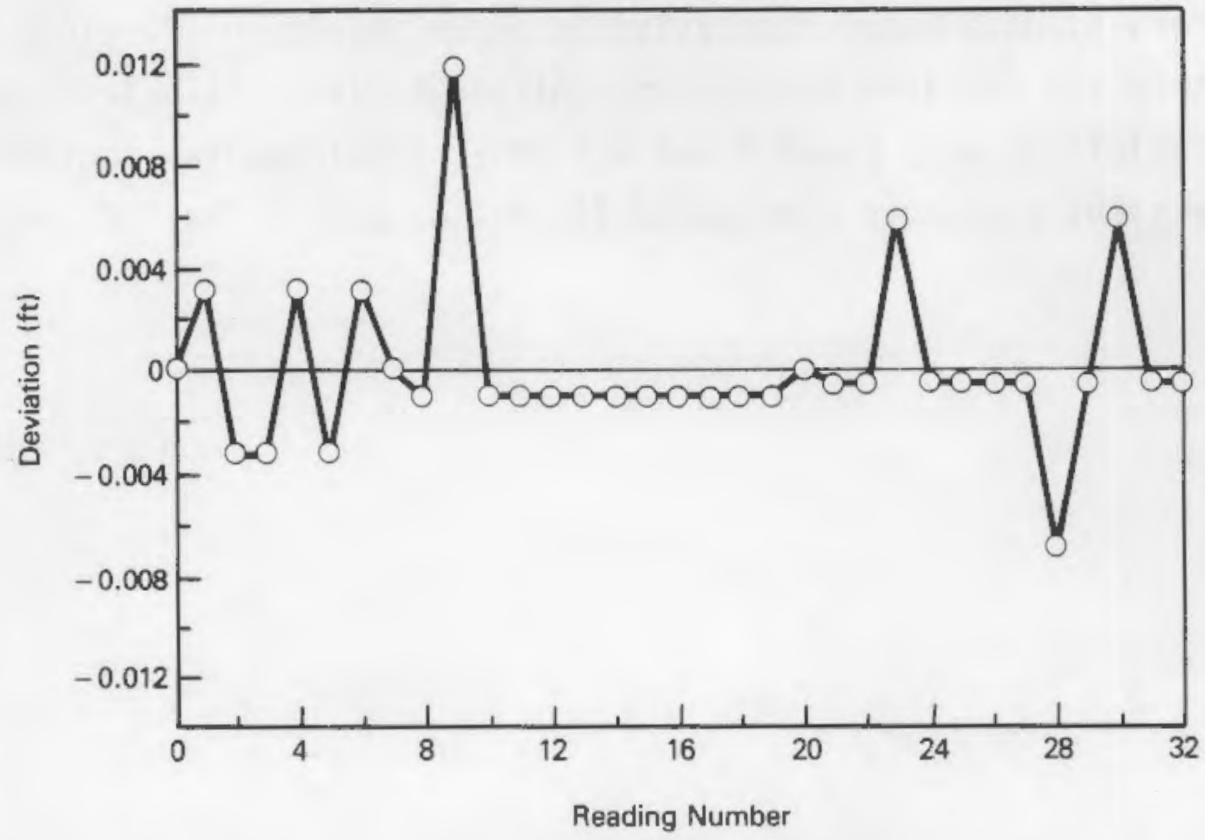

FIGURE 19. Resolution of Millivolt Signal Input to Datalogger S 
Datalogger $U$ was an analog chart recorder. This chart recorder requires a large float for the required precision and cannot operate longer than 8 days without service and is thus disqualified from further consideration.

Datalogger $V$ worked well until the transducer was unplugged without turning the power off; it was returned to the factory for repair. At our request, the vendor repaired the logger, ran a test, and sent the data for our analysis (Figure 20). A 25-ft transducer was used for this test, but the datalogger is an 8-bit machine and does not have the resolution. As mentioned previously, because we were uncertain of the range and resolution requirements at the beginning of the survey, we tested all equipment that was submitted for evaluation.

A summary of transducer performance is shown in Figure 21. The maximum deviation of each transducer reading from its correct calibration value is shown, all on a common scale for comparison. The line showing the maximum allowable deviation is also displayed.

A summary of datalogger resolution is shown in Figure 22, along with a line depicting the required resolution. Although five dataloggers had the required resolution, only $P$ and $Q$ met all other requirements, including having a vapor-tight enclosure that could fit inside a 4-in. well casing. 


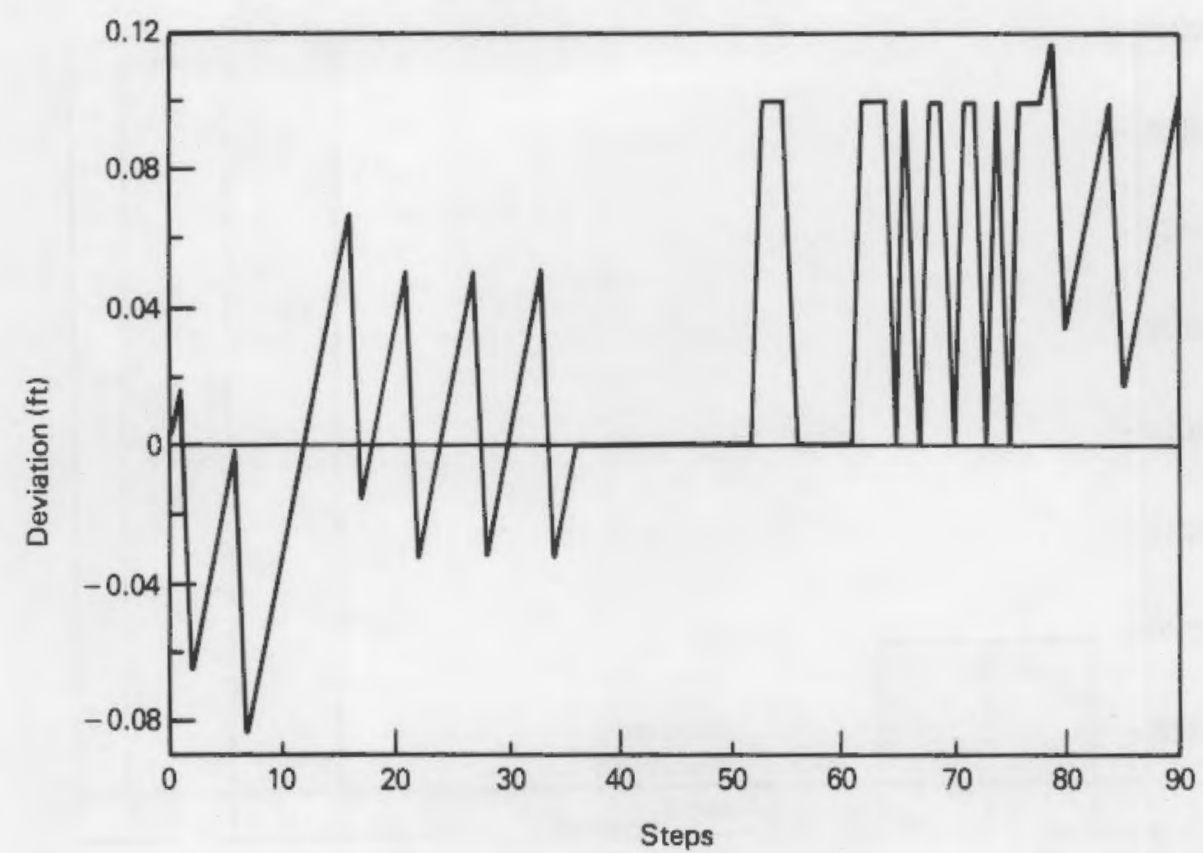

FIGURE 20. Datalogger U Resolution

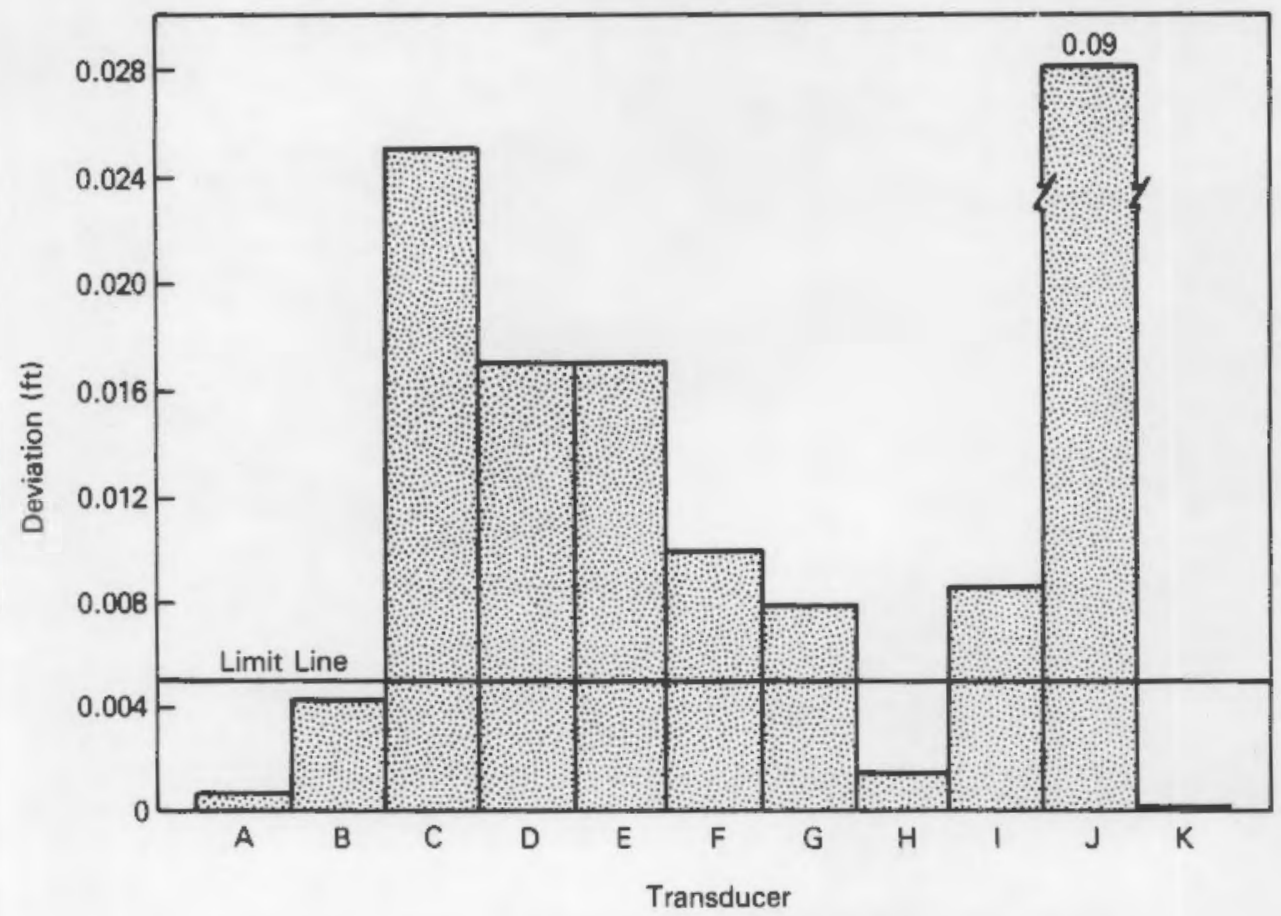

FIGURE 21. Transducer Sensitivity Summary 


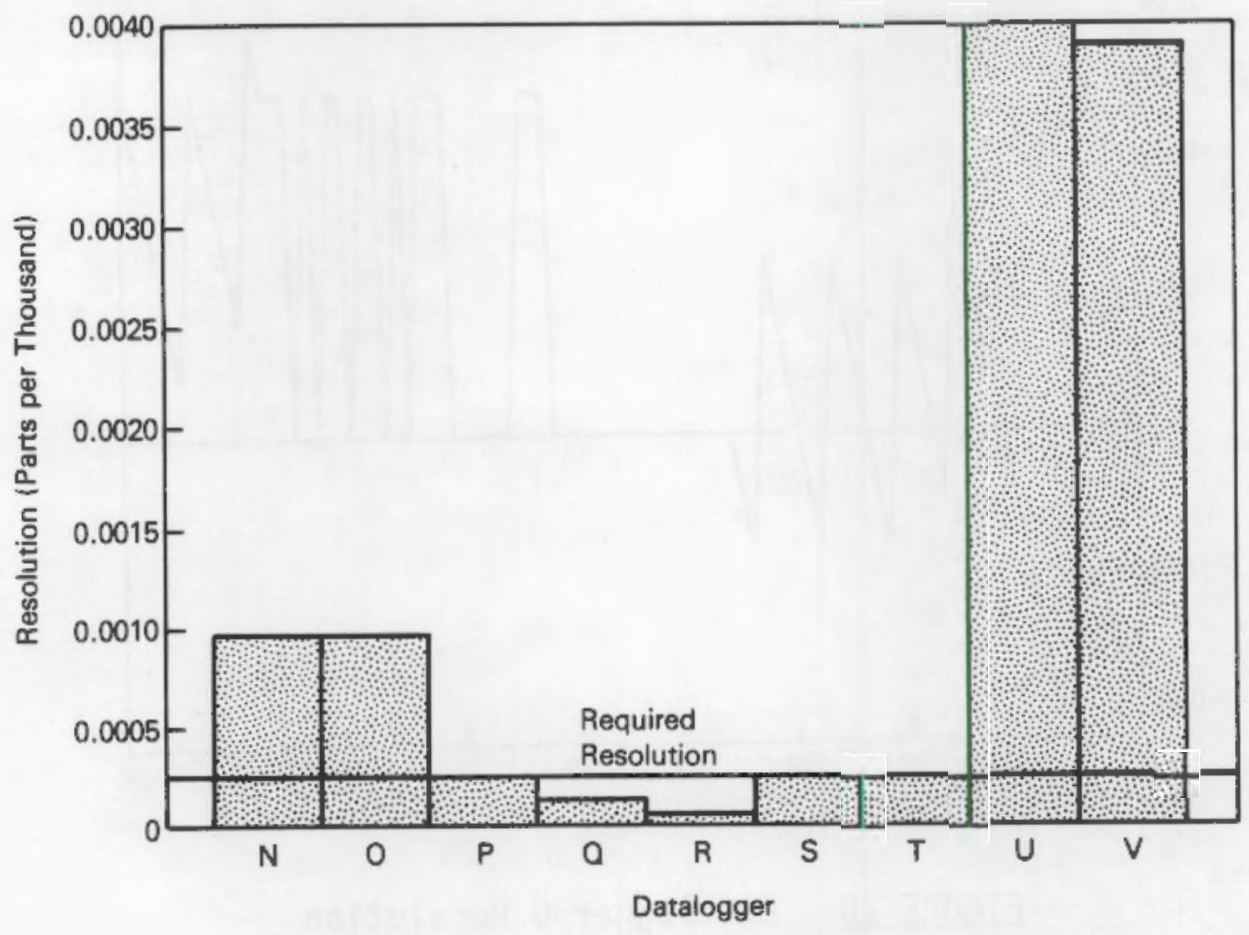

FIGURE 22. Datalogger Resolution Summary 


\section{CONCLUSIONS AND RECOMMENDATIONS}

Aquifer characterization requires measurements of groundwater elevation within $0.01 \mathrm{ft}$ to define flow gradients, directions, and rates. It a]so requires that simultaneous measurements be taken frequent7y enough to define the amplitude and wavelength of the shortest water-level cycle in the aquifer to deduce the time allowable between measurements. Automated datalogging equipment is essential for characterization.

Measurement system requirements include:

- accuracy: $0.01 \mathrm{ft}$ of water elevation

- precision/resolution: $\pm 0.005 \mathrm{ft}$

- hysteresis/drift: $<0.005 \mathrm{ft}$

- range of water pressure to be measured: $\geq 20 \mathrm{ft}$

- size: transducer: $\leq 1$ in. outside diameter and $\leq 12 \mathrm{in}$. long datalogger: capable of fitting inside a 4-in. pipe

- power supply or capacity: $\geq 3$ months of operation from a battery

- sample rate: $\leq 0.1 \mathrm{~s}$

- data storage: $\geq 8760$ data points with time and date

- durability: able to tolerate normal to rough handling during installation and servicing and to operate unattended for at least 3 months

- serviceability: capable of installation and routine field service by moderately trained technicians; capable of data retrieval and battery change without interrupting data collection; capable of transducer replacement without power interruption or element damage

- versatility: adaptable to battery, solar, or municipal power supplies; capable of current, voltage, frequency, and pulse measurements; capable of data storage and retrieval (including FM radio telemetry); tolerant of extreme environments with temperatures ranging from $-25^{\circ}$ to $+140^{\circ} \mathrm{F}$ and humidity ranging from dry to $100 \%$ and condensing

- simplicity: capable of use by technical personnel without special training or special precautions. 
Costs of measuring groundwater levels vary from $\$ 9.00$ per measurement for manually collected data to less than $\$ 0.20$ for hourly data taken automatically. If the time between water-7evel measurements is greater than one week, manual measurements may be more cost effective; if less than one week, automatic monitoring would be more cost effective.

of the equipment tested, 4 of the 11 transducers and 5 of 9 dataloggers provided adequate measurements. Only one datalogger qualified for all applications and transducers. An additional datalogger qualified for a11 applications using the 4- to 20-mA, current-10op transducers. Other equipment lacked one or more of the requirements at Hanford, though nearly all of the equipment tested performed according to manufacturer's specifications.

There was no obvious advantage from either the voltage-bridge or the current-10op transducers. The current-10op devices are advertised for use in areas with high electrical noise. These demonstrations revealed that more electrical noise came from current transmitters than from voltage-bridge transducers when dataloggers were set on low ranges for high sensitivity. When vendors were asked which type of transducer they preferred and why, those that responded reported that the current-loop transducer was preferred because the two-wire system was less costly to construct and easier to monitor when long leads were involved.

Transducer $K$ qualified in all but diameter. Its smallest diameter model is $1.5 \mathrm{in}$. outside. In other characteristics, transducer $K$ is superior to most others demonstrated and is the only one advertised as meeting the longterm drift and temperature compensation requirements. Transducers $B$ and $H$ qualified in the short-term tests, but long-term tests were not run.

Datalogger Q qualified in all respects for all transducers. Datalogger $P$ is less versatile but otherwise qualified for current-loop transducers. Datalogger $T$, mounted in an avajlable weather enclosure, would qualify except for size. Other dataloggers failed to qualify in one or more of the specified categories.

We recommend the following equipment for further field testing: 


\section{Dataloggers}

- Q for any transducer demonstrated here

- P for current-1oop transducers only, such as $C, D, E$, or $F$.

Note: These datalogging systems have sealable enclosures and $\mathrm{FM}$ radio telemetry.

\section{Transducers}

- $K$ (despite its 1.5- to 3.5-in. minimum dianeter limitation)

- $A$ and $B$.

Note: Transducer $K$ is available with a 4- to 20-mA current-100p transmitter or with an internal processor that gives RS-232 output, ready for FM radio telemetry or computer input. 



\section{REFERENCES}

Campbe17, M. D., and R. Schalla. 1990. Field Tests of Automatic Water-Level Monitor Systems: Technology Development Program--Site Investigation Technology Project. PNL-7497, Pacific Northwest Laboratory, Richland, Washington.

Leupold and Stevens, Inc. 1987. Stevens Water Resources Data Book. Fourth Edition. Beaverton, Oregon.

U.S. Environmental Protection Agency (EPA). 1986. Resource Conservation and Recovery Act (RCRA) Ground-Water Monitoring Technical Enforcenent Gujdance Document, OSWER-9950.1, Washington, D.C. 


\section{DISTRIBUTION}

No. of

Copies

\section{OFFSITE}

12 DOE/Office of Scientific and Technical Information

F. Fong

U.S. Department of Energy

San Francisco Operations

Wells Fargo Bank Building

1333 Broadway

Oakland, CA 94612

J. Mathur

U.S. Department of Energy DP-123 (GTN)

Washington, DC 20545

F. Wobber

U.S. Department of Energy

Office of Health and

Environmental Research

ER-75

Washington, DC 20545

S. M. Ange 1

Lawrence Livermore

National Laboratory

Environmental Sciences

Division

P.0. Box 5507, L-524

Livermore, CA 94550

M. Carrabba

EIC Laboratories

111 Downey Street

Norwood, MA 01062

W. Chudyk

Civil Engineering Department

Anderson $\mathrm{Ha} 11$

Tufts University

Medford, MA 02155
No. of

Copies

G. Coffey

Savannàh River Westinghouse Company

P.0. Box A

Aiken, SC 29808

E. Coglin

EPA/EMSL

P.0. Box 93478

Las Vegas, NV 89193-3478

D. Eastwood

Advanced Technology Project Office Lockheed Engineering and Sciences

Company

Environmental Programs Office

1050 E. Flamingo Road, Suite 120

Las Vegas, NV 89119

L. Eccles

EPA/EMSL

P.0. Box 93478

Las Vegas, NV 89193-3478

N. E. Rothermich

Oak Ridge National Laboratory

HAZWRAP Support Contractor office

Oak Ridge, TN 37831

H. Randy Sweet

Sweet-Edwards/EMCON

603 Royal West

Kelso, WA 98626

J. Thomas

Fiberchem, Inc. 3904 Juan Tabo NE

A]buquerque, NM 87111

J. Wang

Department of Chemistry

New Mexico State University

Las Cruces, NM 88003 
No. of

Copies

ONSITE

4 DOE Richland Operations office

P. K. CTark

R. E. Gerton

G. W. Rosenwald

K. M. Thompson

7 West inghouse Hanford Company

M. R. Adams

J. W. Cammann

A. G. Law

S. J. Phillips

J. F. Relyea

C. R. Stroup

R. M. Wirsing

\section{Pacific Northwest Laboratory}

J. V. Borghese

J. W. Brothers

R. W. Bryce

M. D. Campbell (10)

R. L. Cheatham

R. M. Ecker

J. C. Evans
No. of

Copies

J. W. Falco

G. W. Gee

J. M. Gephart

R. E. Gephart

T. J Gilmore

D. S. Goldman

J. W. Griffin

J. M. Hales

P. C. Hays

D. D. Hostetier

C. T. Kincaid

W. W. Laity

G. V. Last

S. P. Luttrell

E. M. Murphy

D. R. Newcomer (5)

K. B. 01 sen

N. J. 01 son

W. T. Pennell

R. G. Riley

R. Schalla (10)

R. L. Skaggs

R. M. Smith

T. L. Stewart

J. E. Szecsody

P. L. White

Publishing Coordination

Technical Report Files 